\title{
Manifestómetro: recuento de multitudes y significados de la movilización ${ }^{1}$
}

\author{
RAMÓN ADELL ARGILÉS \\ Departamento Sociología I \\ U.N.E.D. \\ radell@poli.uned.es
}

Recepción: enero 2005

Aceptación: abril 2005

«Un sistema que no falla, consiste en contar las piernas de los asistentes y dividir por dos» (anónimo).

\section{CÁlCULO DE MASAS: INTERÉS Y LIMITACIONES}

Si un libro se anuncia como las «mil y una recetas de cocina», no nos sorprenderá si en su interior encontramos cientos de recetas, pero no las 1.001 que pregona la portada. Igualmente, cuando Moustaki ${ }^{2}$ se refería a que «somos dos, somos tres, somos mil veintitrés...» en su canción, aludía así (individuo, pareja, más de mil) a la pujanza de un movimiento contestatario y no a un recuento objetivo de movilizados. Hace unos años en una carga policial, tuve ocasión de escuchar de boca de un mando policial, la orden -imposible de cumplir- de «disuélvanse en grupos de a medio».

Anéctotas aparte, desde la Revolución Francesa, la interpretación de los fenómenos de masa, como uno de los motores clave del cambio social, ha ocupado, como miedo o como esperanza, un lugar central. En contextos democráticos, la suma de votos es la única cuantificación política reconocida, y la suma de encuestados la única extrapolación determinante de la realidad social. Finalizado el siglo de las masas, se anuncia a bombo y platillo, la llegada de la era del individuo, y por tanto del sacrificio de lo colectivo, en aras del yo. Las «masas» se vuelven cualificadas y simbólicas. Como escribió el poeta español Antonio Machado, «por muchas vueltas que le doy —decía Mairena - no hallo la manera de

\footnotetext{
1 Este trabajo es una reelaboración y actualización de la ponencia presentada en el VIII Congreso de la FES (Federación Española de Sociología), grupo de trabajo movimientos sociales y acción colectiva, en Alicante (septiembre 2004).

${ }^{2}$ Moustaki, George (1971): Nous sommes deux. Polydor.
} 
sumar individuos». Siendo conscientes de que los grupos, la masa, el pueblo, o la ciudadanía es mucho más que una mera suma de individuos, intentaremos, no obstante, adentrarnos en la cuantificación y significado de los fenómenos colectivos.

Podríamos plantear, como hipótesis previa, que de siempre el cálculo, la aritmética o las matemáticas son necesarias para justificar o mantener las relaciones de poder y dominación. Para Lizcano, sí existe una «matemática burguesa» o «matemática ilustrada». «A diferencia de otras, esa matemática manifiesta, ya desde su nacimiento, una decidida vocación antipopular. Vocación antipopular que llega hasta nuestros días cuando, por ejemplo, políticos, economistas y burócratas descalifican razones y argumentos por la sola, pero rotunda, razón de que no se ajustan a los cálculos o se basan en cálculos erróneos» (Lizcano, 2002: 6). Así pues, «la política clásica está fundada sobre la razón y los intereses. Se condena a la impotencia, ya que sigue la lógica de la ciencia y trata a la masa como una suma de individuos» (Moscovici, 1981: 51). El cálculo, aplicado en todos sus ámbitos, se vuelve determinante en el contexto actual de «sociedad de riesgo». «Somos conscientes de que la técnica permite dominar las energías materiales, pero también ha implantado de manera masiva una mentalidad exclusivamente basada en el cálculo. Una lógica perfectamente adecuada para las máquinas artificiales y que, por desgracia, es aplicada a las sociedades humanas, que no son máquinas en el sentido determinista, trivial.» (Morin, 2004: 58-59).

La cuantificación de la movilización no es baladí ya que históricamente «la medición numérica de la hegemonía se basa en ciertos supuestos: la igualdad de todos los hombres, el principio de representatividad, el derecho de la voluntad mayoritaria. La ley del número remite así a la ley de la proporción. El orden radica en la justa proporción» (Lechner, 1986: 61). Desde este ángulo, puestos a convocar movilizaciones en la calle y a contar a sus asistentes, las promovidas por un gobierno (y sus aparatos mediáticos) serán casi siempre más numerosas. Recordemos que el «poder de la calle» hay que analizarlo con parámetros distintos de los del poder político (número de votos, por ejemplo), pero evitando también posibles espejismos (tanto en la cantidad como en la calidad de la participación).

Como nos recordaba Jesús Ibáñez, el sistema democrático hereda de Atenas la medida del voto y de Esparta recibe la medida del grito (a ver quiénes gritan más a favor de una decisión u otra $)^{3}$. «El voto mide la extensión de la voluntad, pero el "ruido" mide también su intensidad» (Ibáñez, 1997: 173). ¿Cómo medir ese «ruido»? Desde la Etnometodología ${ }^{4}$ se nos recuerda que «las estructuras sociales que llamamos sistema de clasificación (estratificación) social o formas de organización política han de ser recreadas relacionándolas con el modo como los actores arreglan sus asuntos en las circunstancias cotidianas. Así, el mundo fenoménico del actor es de un interés primordial» (Cicourel, 1982: 11). En esta e

3 «En las cortes franquistas como los votos eran unánimes, los periodistas inventaron el aplausómetro para medir la duración y la fuerza de los aplausos» (Ibáñez, 1997: 63).

4 Ver trabajos de García Ferrando, Ibáñez, Alvira, Cicourel, etc. 
«nota de investigación» partimos de la idea de que el ruido o el grito colectivo nos ayudarán a interpretar a las mayorías extensivas (sociedad activa) frente a la dimensión clásica de mayorías/minorías intensivas (elites). No se presenta aquí una teoría de la multitud y, por tanto, «a menos de tener teorías consistentes no podemos decidir en qué medida un método particular y los datos que produzca nos dirán algo que merezca la pena conocer» (Cicourel, 1982: 18).

La obsesión por la cifra de asistentes a una reunión pública se muestra determinante ya a la hora de establecer la propia legalidad o no de la acción colectiva. Según la legislación ${ }^{5}$, se considera manifestación cuando los asistentes son más de veinte. Así, diecinueve personas mostrando pancartas no son manifestación. Será por tanto una petición, una mesa de recogida o entrega de firmas, un acto simbólico, una lectura de un comunicado, pero técnicamente no es una reunión pública de las que ampara el artículo 21 de la Constitución Española de 1978. Este tipo de reuniones no requieren ni permiso ni comunicación. Si son veintiuno o más, la reunión adquiere rango de reunión pública (manifestación o concentración) ${ }^{6}$. Junto a esta preocupación por el número mínimo de manifestantes se da el caso opuesto: la indiferencia del recuento ante reuniones multitudinarias. En una primera lectura, si se habla en los media de un millón de manifestantes se refieren a que fueron muchísimas personas (cientos de miles o medio millón, arriba o abajo), lo cual justifica la convocatoria y avala, con masiva contundencia, su demanda. En estos casos, se dice que ante la cantidad de personas congregadas, cifras para qué ${ }^{7}$.

En el tema que nos ocupa, ¿por qué no se cuantifican de una forma objetiva, o al menos aceptable, las protestas de modo que cada cual pueda evaluar los éxitos o fracasos de la movilización? El debate es actual. Como afirma Josep María Casasús, Defensor del Lector de La Vanguardia, contestando al lector W. Espina, «el acto de contar manifestantes es uno de los grandes retos planteados al periodismo por la cultura cuantitativa que se ha impuesto a lo largo de la modernidad» (Casasús, 2001). Por su parte, Alex Grijelmo (por entonces periodista de El País, y hoy presidente de la Agencia Efe) reconoce también la importancia que tiene esa información y el rigor necesario de informar, resaltando que «el número de participantes en una concentración o acontecimiento público se ha convertido en pieza fundamental del relato informativo, ya se trate de un recital de cantautores o de una manifestación contra el terrorismo. Tradicionalmente, los periodistas calcularon estas cifras a ojo. Y eso se sigue haciendo» (Grijelmo, 1997: 156).

\footnotetext{
${ }^{5}$ La Ley Orgánica $9 / 83$ define una reunión como «la concurrencia concertada y temporal de más de veinte personas, con finalidad determinada».

${ }^{6}$ No es casual, por tanto, que grupos como Greenpeace, o el Sindicato Unificado de Policía, realicen protestas de 18 o 19 personas, para no infringir así la Ley de Reunión o Manifestación.

${ }^{7}$ Los redondeos y las unanimidades son siempre sospechosas. Así por ejemplo, en la concentración de la Pza. Oriente el 20-N de 1976 las cifras que se ofrecieron fueron: Policía Municipal $>300.000$, Rne $>200.000$, El País $>100.000$, EPress $>$ entre 125.000 y 150.000 . Añorando «el millón», al día siguiente, el periódico El Alcázar (22-11-1976) salió con el título “¿Cifras? ¿Para que?» en el que se antojaba inútil un recuento de asistentes por considerar que allí estuvo presente toda España.
} 
Cuál sería entonces la fórmula aplicable. Casasús opina que «no existe una fórmula segura, precisa, estable e indiscutible para calcular el número exacto de participantes en una manifestación, del mismo modo que no la hay para otras situaciones de la misma naturaleza. Pero en una cultura cuantitativa como la dominante, operar con convenciones numéricas, aunque parezcan absurdas o no ecuánimes, contribuye a la convivencia política (en las elecciones gana el que tiene un voto más que los otros), a la regulación académica (se aprueba con 5 y se suspende con 4,9), y a la fe deportiva (la gloria es para los que marcan el gol que desempata, y para quien cruza la meta un segundo antes que otro). Si todas estas situaciones se midieran con criterios de calidad en lugar de cantidad tal vez se haría más justicia, pero habría más discusiones y tensiones de las que existen a pesar de estos convencionalismos aritméticos.» (Casasús, 2001).

Grijelmo, propone: «Lo más sencillo - cuando el acto público no se celebra en un lugar cuyo aforo se conoce - es acudir al callejero de la ciudad para, utilizando la escala correspondiente, medir el espacio que ocupaban los manifestantes en el momento de terminar la marcha. A continuación, se calculan tres o cuatro manifestantes por metro cuadrado - según la densidad de la concentración humana - y se multiplican por la superficie total. He ahí un buen método para saber cuántas personas han acudido. Y mejor aún resultará si le explicamos al lector cómo lo hemos calculado» (Grijelmo, 1997: 156).

Las cifras que normalmente ofrecen los medios de comunicación no son propias, y proceden de Agencias de Prensa (Efe, Reuters, Europa Press). En muchos casos no ofrecen una cifra, sino tan sólo una apreciación tal como «algunos, un grupo, centenares, numerosas personas, una multitud, decenas, centenares, miles». Si se dan cifras redondeadas, suelen ir acompañadas de matices valorativos tales como «cerca de diez mil, más de mil, apenas un centenar, sólo cincuenta, etc.», añadidos en muchos casos por el medio que finalmente difunde la noticia, tratando así de redimensionar en parte el resultado. En aras de la inmediatez, pocos medios y en pocos casos recurren a la medición propuesta, por juzgarla irrelevante y costosa. A ello hay que añadir la legítima línea editorial del periódico más presiones que interfieren en el demagógico campo de las cifras. Minimizar o magnificar el conflicto siempre ha sido una tentación. En el debate (aquí propuesto) estos tres periodistas admiten también presiones en este sentido. «Tengo experiencia de enormes presiones en mi despacho de entonces director en funciones de El Correo Catalán de ciertas fuerzas y personajes políticos, hoy relevantes, para que titulara con una cifra descaradamente abultada, pese a que la realidad era otra. Tuve que ingeniármelas poniendo las cifras dadas por "los organizadores" y las "oficiales" y añadir las que el periódico estimaba más verosímiles. Pero estos trucos no bastan» (Espina, 2001).

Por su parte, Grijelmo se rebela también contra la falta de rigor, el mimetismo y la complacencia de ciertas convocatorias unitario-institucionales. «A veces ni siquiera se da la posibilidad de cotejar el dato de un diario con los del resto de la prensa: el consenso en materias delicadas falsea también la realidad, como ocurrió con la manifestación contra el terrorismo celebrada el 19 de febrero de 1996 en 
Madrid tras el asesinato del jurista Francisco Tomás y Valiente. Todos los periódicos de Madrid titularon que un millón de personas - cifra mágica, por lo que se ve- habían participado en la marcha de protesta. Y no era verdad». Seguidamente Grijelmo expone sus cálculos en función de superficie y densidades ${ }^{8}$, para afirmar a continuación: «Pero, al tratarse de una manifestación contra el terrorismo, nadie -ni siquiera el diario El País, que lo tiene obligado por su Libro de Estilo- quiso publicar ese cálculo, y todos dieron por buena la cifra facilitada por los organizadores. De lo cual discrepo: odiamos el terrorismo, pero también la mentira: amamos la democracia, pero debemos amar más la verdad, En ocasiones -muy escasas- puede justificarse la omisión de una noticia (por ejemplo, informar sobre la detención de un terrorista cuando la difusión del hecho puede facilitar la huida de sus compañeros a los que se prevé detener a continuación). Pero nunca se puede justificar la publicación de una falsedad» (Grijelmo, 1997: 156).

«Ante la ausencia de un "manifestómetro" aceptado por todos, la buena práctica profesional en la prensa exige que los periodistas presenten los resultados de sus cálculos al margen de las cifras que dan las partes enfrentadas: organizadores y autoridades. Es un deber profesional. Los lectores delegan en los periodistas la tarea de verificar» (Casasús, 2001). Veamos ahora algunos de los métodos y técnicas, al uso, para el recuento de grupos, masas y multitudes.

\section{MÉTODOS Y TÉCNICAS PARA EL RECUENTO DE MULTITUDES}

A nadie se le escapa la problemática que se plantea cuando se intenta un recuento fiable de manifestantes. A priori, el éxito inmediato o fracaso político de toda movilización se centra principalmente en el número de personas que forman la masa reunida, y en el comportamiento (pacífico o violento) de los individuos que la integran. Al menos ello se desprende de las declaraciones habituales de los poderes y actores colectivos. Partimos de la hipótesis de que estas dos variables (número de asistentes y actitud de los mismos) influirán, en gran medida, en el éxito o fracaso último de la campaña de movilización y en el logro o no de la demanda origen del conflicto. Por ello hay que calcularlas con el máximo rigor posible.

A continuación se describen brevemente - a modo de manifestómetro- diversas técnicas empleadas para evaluar con cierta aproximación la asistencia en las movilizaciones de grupos, masas y muchedumbres. Con ellas nos acercaremos algo más al número real de asistentes (Adell, 1989), (Fillieule, 1996), (Favre, 1990), (Almirall, 2000).

${ }^{8}$ Cálculos de asistencia en la manifestación del 19-2-1996 (según Grijelmo-El País):

Pta. Sol $7.500 \mathrm{~m}^{2}$.

C/ Alcalá $40.000 \mathrm{~m}^{2}(\times 4=160.000)$.

Pza. Cibeles $30.000 \mathrm{~m}^{2}(\times 3=120.000)$.

Paseo de Recoletos $5.000 \mathrm{~m}^{2}(\times 3=15.000)$.

Paseo del Prado y Colón $12.500 \mathrm{~m}^{2}(\times 4=50.000)$.

Recorrido total de la manifestación: $95.000 \mathrm{~m}^{2}(=382.000$ a 450.000$)$. 
Algunos criterios para la medición llegan a establecer, por ejemplo, índices de densidad de manifestantes por metro cuadrado, o de la velocidad de paso de estos. Ello puede realizarse también tras una ampliación de fotos aéreas (en caso de que existan) o panorámicas generales ampliadas a una escala manejable para dicho cálculo. Veamos los dos principales criterios.

\subsection{Superficie y densidad}

El criterio de medición por $\mathrm{m}^{2}$ supone la delimitación sobre un plano de la superficie ocupada por los concentrados. Veamos un ejemplo: En la Concentración Nacional en la plaza de Oriente de Madrid, con ocasión del $3 .^{\circ}$ aniversario de la muerte de Franco (18 noviembre 1978) las cifras de asistencia ofrecidas oscilaron entre el millón de los organizadores, entre 250.000 y 300.000 personas según la policía municipal y las 150.000 de la agencia Europa Press. La foto de la plaza (inédita) (ver Figura 1) nos permite diseñar una cuadrícula a escala

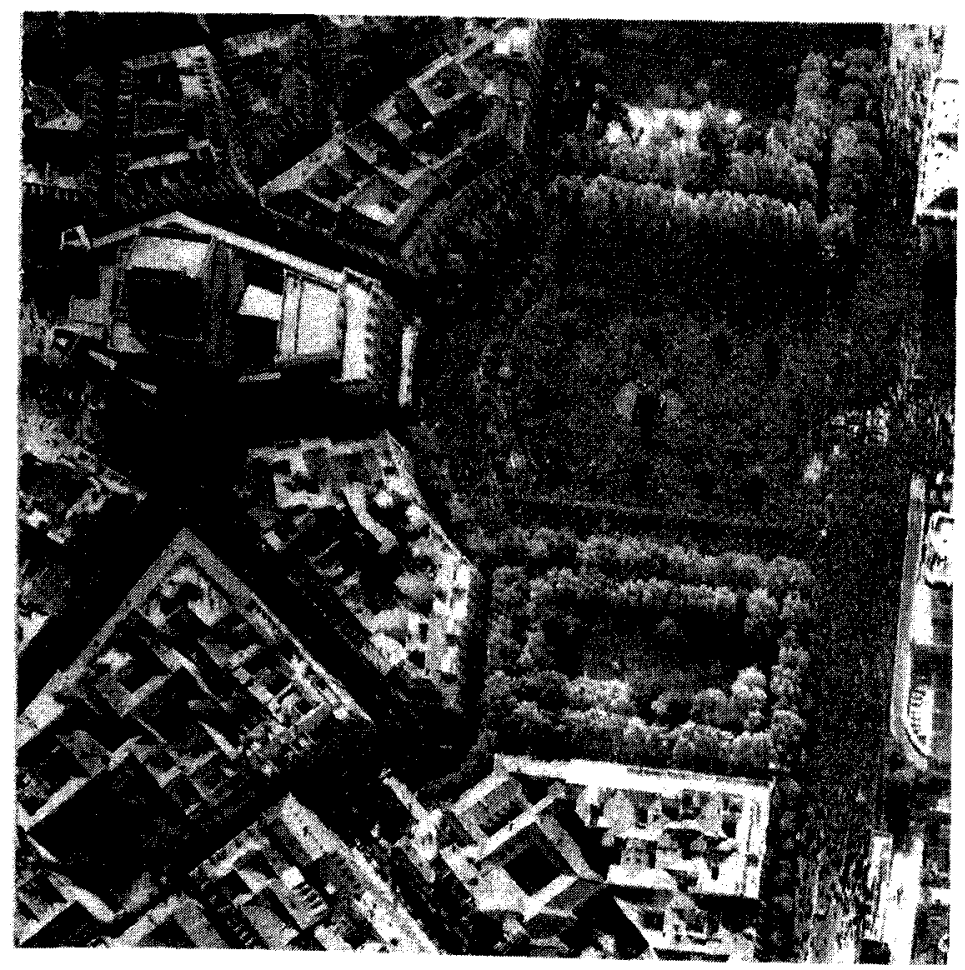

Figura 1. Concentración del 18 de noviembre de 1978, en la plaza de Oriente (Madrid). 
$(1 \times 10 \mathrm{~m})$ y atribuirle zonas de densidades por metro cuadrado $\left(4 \times \mathrm{m}^{2}, 3 \times \mathrm{m}^{2}\right.$, $2 \times \mathrm{m}^{2}$, etc.) (ver Figura 2). Aplicando esta técnica, y según nuestro recuento, asisten unas 138.500 personas.

En una manifestación, supone la medición de la distancia de la cabecera hasta el final o cola del recorrido. Los metros cuadrados del total de la superficie abarcada por los manifestantes nos mostrarán la extensión de la masa. Por tanto, toda superficie tiene un «área útil» en donde cabe la masa fluida que ocupa y administra ese espacio. Hay que descontar de ellos los metros ocupados por vehículos, árboles, distancias entre cortejos, etc. Cuando la zona cuadriculada es muy densa se calcula un máximo de 4 personas $\mathrm{m}^{2}$ (tapón de cabecera, concentraciones en espacios pequeños, paradas del cortejo). En otras zonas se calculará de 1 a 2 personas por $\mathrm{m}^{2}$. Las densidades son variables en una misma movilización, lo cual excluye los cálculos sistemáticos. Cuando los manifestantes están andando suele medirse a 1 por $\mathrm{m}^{2}$. También tenemos excepciones, por ejemplo, en caso de lluvia se presupone la existencia de un manifestante por paraguas $\left(\mathrm{m}^{2}\right)$,

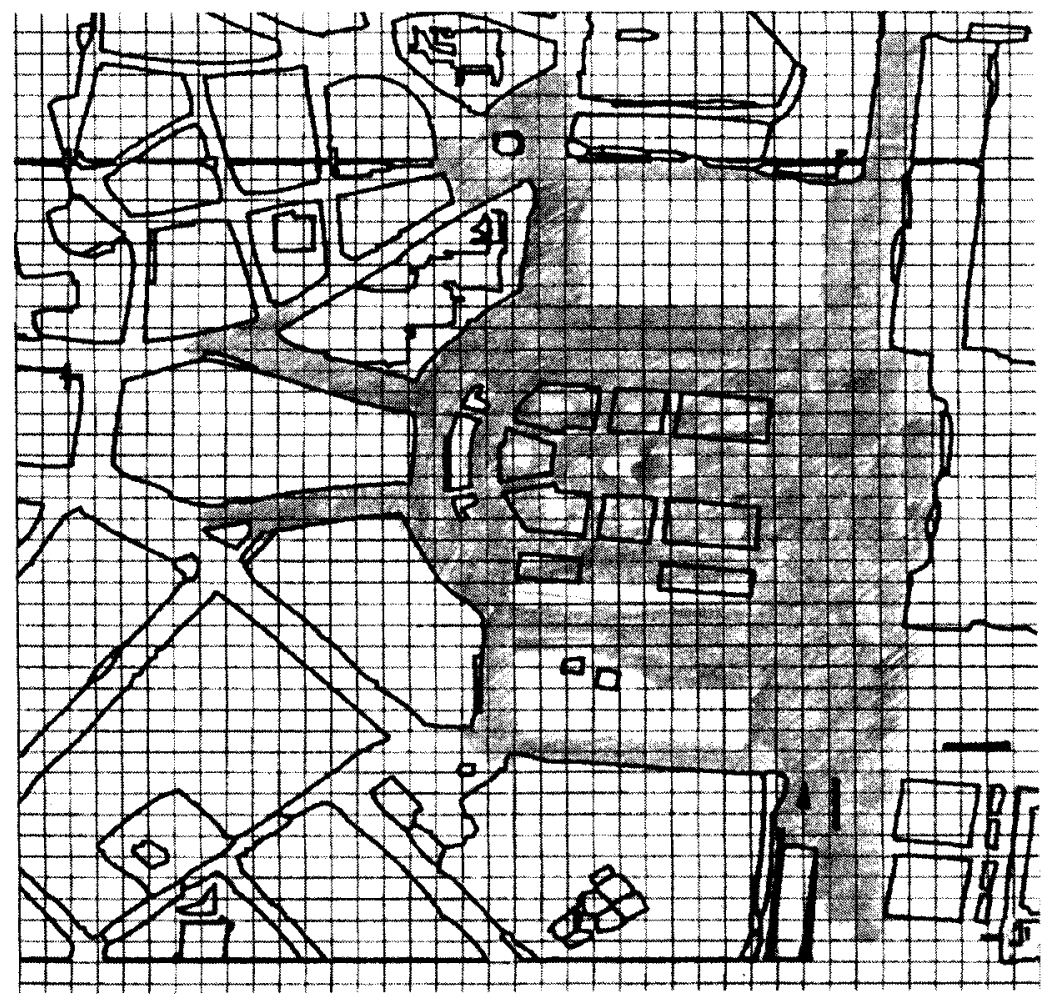

Figura 2. Aforo plaza de Oriente, el 20-N-78: cuadrícula a escala 1:10. Total: 138.500 asistentes. 
si bien, en caso de chaparrones inesperados cada paraguas puede llegar a proteger a cuatro manifestantes $/ \mathrm{m}^{2}$ (como por ejemplo, en algunas zonas de la manifestación del 12 de marzo 2004, tras el 11-M en Madrid).

Esta metodología de superficie y densidad, ha sido utilizada con notables e interesantes resultados por el equipo de Barcelona denominado Contrastant.net. Desde su página suelen ofrecer en internet cifras propias de las grandes movilizaciones celebradas en Barcelona. Inspirado por Miquel Almirall, a quien el profesor de periodismo y ensayista, Arcadi Espada, describe como «héroe civil que hace muchos años que cuenta manifestantes». Podría criticarse, como origen de posibles sesgos, la procedencia independista del equipo de profesores de enseñanza media que lo integran pero ello no impidió su crítica a la histórica «manifestació de la Diada» de Barcelona del 11 de setembre de 1977, con un análisis - a posteriori- en donde rebaja la cifra de más de un millón de asistentes de entonces ${ }^{9}$ a tan sólo 246.485 . Este tipo de iniciativas, junto a las de agencias de contrainformación (Indymedia, Nodo50, etc.) facilitan más puntos de vista, y por tanto son siempre necesarias para el conocimiento de las dimensiones del conflicto.

La dificultad de obtener imágenes aéreas, la movilidad de los asistentes y la falta de mapas urbanos actualizados, complican más estas mediciones en el caso de grandes aglomeraciones humanas. Además, no estamos exentos de percepciones equivocadas o «politizadas» que conllevan cálculos erróneos. Un ejemplo de ello lo tenemos en la Huelga del 20-J (20-06-2002) contra el decretazo «Empleo y protección social son tus derechos, que no te los quiten». Para los organizadores (CCOO, UGT, USO, ...), asisten en Madrid 500.000 personas (con un total de 4.500.000 en las 89 manifestaciones en todo el Estado), mientras que desde la Delegación de Gobierno se ofreció, en un primer momento, la cifra de 20.000 asistentes, si bien se rectificó al cabo de unas horas para duplicarla, fijando el cálculo final en 40.000 manifestantes. Para Tve1, decenas de miles. Según cálculos propios, cerca de 190.000. Las distintas mediciones sobre el terreno tampoco son coincidentes. Como si de espacios urbanos espongiformes se tratara, tenemos dos visiones aportadas por los periódicos El País ${ }^{10}$ (expansiva) y La Razón ${ }^{11}$ (restrictiva) que difieren sustancialmente entre sí en cuanto a superficies y densidades «demostradas».

${ }_{9}$ El País $>1.500 .000$ (1/4 de los catalanes), La Vanguardia > más de 1.500.000, Guardia Urbana $>1.200 .000$, Interviu $>1.000 .000$, Hoja del Lunes $>$ más de 1.000 .000 .

${ }^{10}$ Manifestación 20-J (según El País, el 22-6-2002):

C/ Alcalá $56.000 \mathrm{~m}^{2}$ aprox $(\times 4=160.000)$.

Pza. Cibeles $16.000 \mathrm{~m}^{2}$ (of.) $(\times 3=120.000)$.

Pta.Sol $12.000 \mathrm{~m}^{2}$ (of.).

Recorrido total de la manifestación: $84.000 \mathrm{~m}^{2}(=252.000$ a 336.000$)$.

1 Manifestación 20-J- (Según La Razón, el 24-06-2002):

1-Pza. Cibeles/bellas artes $6.000 \mathrm{~m}^{2}$.

2-C/ Alcalá Bellas Artes/Sevilla $4.800 \mathrm{~m}^{2}$.

3-Sevilla/Pta. Sol $3.150 \mathrm{~m}^{2}$.

4-Pta. Sol/Montera Carretas $2.660 \mathrm{~m}^{2}$.

5-Pta. Sol/Correo Preciados $5.600 \mathrm{~m}^{2}$.

Recorrido total de la manifestación: $22.210 \mathrm{~m}^{2}(\times 2=44.000 \mathrm{o} \times 3=66.000)$. 


\section{Helicópteros y avionetas}

En Madrid, las manifestaciones de varios millares de personas son sobrevoladas (y grabadas parcialmente) por el helicóptero de la Policía Nacional. En contados casos, las televisiones u organizadores hacen un seguimiento aéreo (desde helicópteros, avionetas o incluso desde tejados) de estos actos. En actos masivos la publicación y análisis de imágenes aéreas obtenidas desde helicópteros y avionetas harían posible recuentos más certeros. No es habitual su difusión (por ejemplo las de la manifestación del 15 de febrero 2003 contra la guerra?) y, cuando se presentan, no son infalibles tampoco. Así por ejemplo, recientemente durante una manifestación de protesta contra el futuro puerto industrial de la Granadilla, celebrada el 27 de noviembre 2004 en Santa Cruz de Tenerife, el presidente autonómico canario, Adán Martín, defendió el uso de una avioneta (empresa Grafcan) para contar el número de manifestantes que se oponen al proyecto. La Subdelegación del Gobierno en Santa Cruz calculó que había 20.000 personas, basándose en los cálculos de la avioneta (20.175) y se facilita una sola foto (de las 15,02h) con 12.976 manifestantes. A la guerra de cifras, se añaden otras fuentes: Tv Canaria: 12.000, Policía Nacional: 22.000, Policía Local: 45.000 , y organizadores: 110.000. Lejos de zanjarse la polémica, el grupo ecologista ATAN (2004) alegó, con razón, que la hora de la foto no recogía el momento cumbre de la reunión. Por otra parte, ATAN retoca la foto (ver Figura 3) - aumentando los asistentes a 200.000 - para con ello demostrar

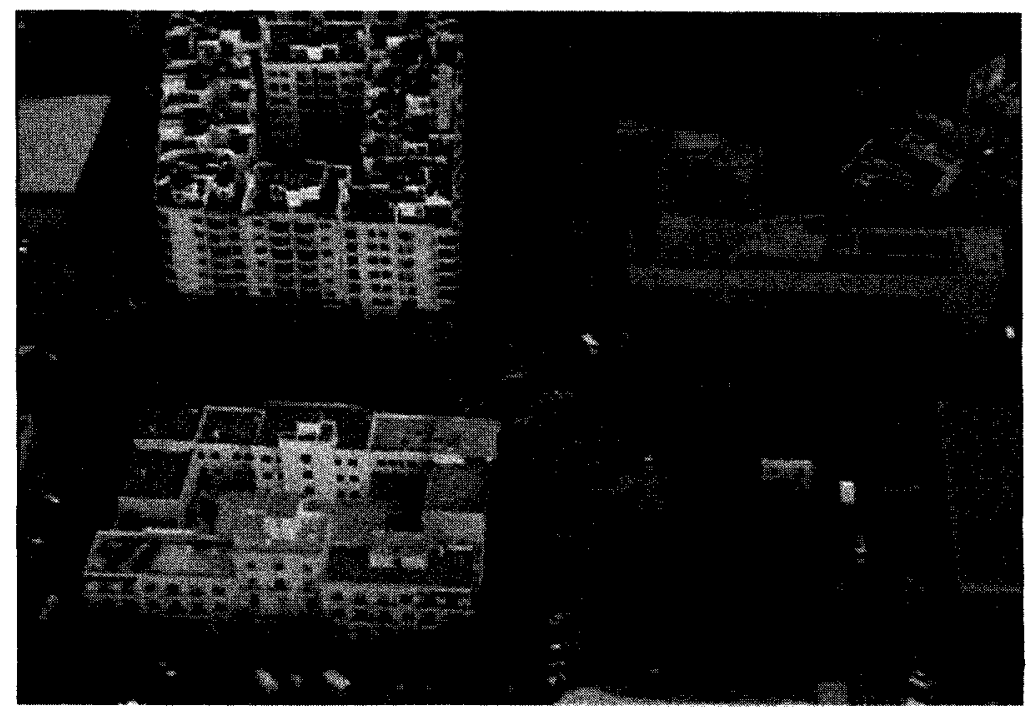

Figura 3. Manifestación del 27 de noviembre de 2004 en Santa Cruz de Tenerife. Foto de Grafcan, retocada por ATAN aumentando los asistentes a 200.000. 
que las fotos aéreas también son manipulables. En respuesta a una pregunta del diputado del grupo Socialista Santiago Pérez (Efe, 22-12-04) Adán Martín justificó la contratación de la avioneta, «con el objetivo de aportar un conocimiento objetivo a la verdad», y aseguró que el coste de este instrumento fue «muy poco».»Sabíamos que iba a haber discusión sobre el número de personas» que acudían a la manifestación. Las fotografías aéreas «dan lo que dan y cien mil personas desde luego no había». En su defensa reiteró que el uso de la avioneta es «simplemente conocer la verdad, que no puede estorbar a nadie». Cabría añadir que, recientemente, en todas las grandes ciudades existe también un servicio público de información al tráfico, en donde los internautas tienen a su disposición la visión de las imágenes que recogen las cámaras urbanas situadas en las principales vías públicas (ver Figura 4). En caso de grandes eventos el sistema queda, en aras de la seguridad, «temporalmente fuera de servicio».

\subsection{Ancho y número de filas}

El otro interesante criterio consiste en contar el número de personas que incluye el ancho de la fila, así como el número de filas que siguen tras la primera.

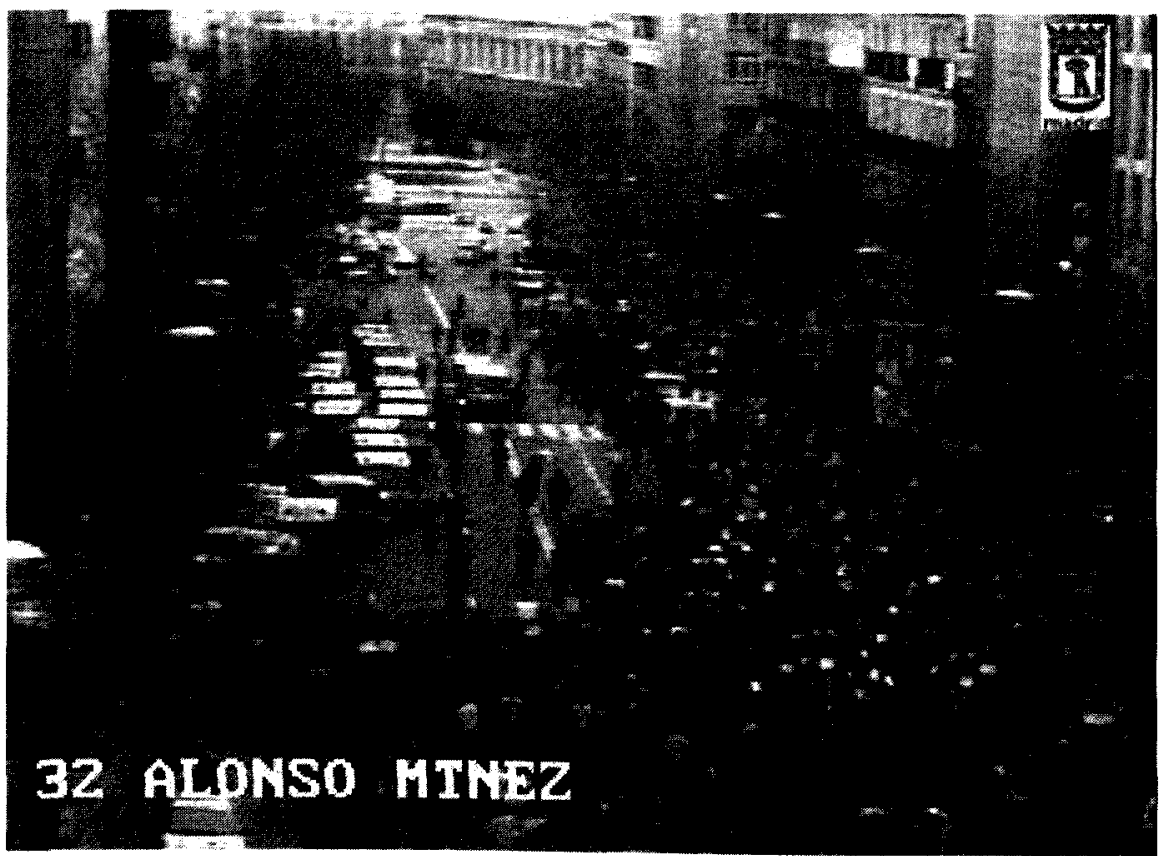

Figura 4. 13 de marzo 2004, 18,20 horas, calle Genova ante la sede del PP (Cámaras de tráfico del Ayuntamiento de Madrid). 
Estos cálculos se realizan en tres o al menos dos puntos distintos del recorrido. $\mathrm{El}$ observador deberá situarse en un estrechamiento o ralentí de la marcha. Se toma la hora de inicio de la marcha así como la de finalización (tiempo de paso). Se anotan también los tiempos de parada o ralentí y con ello obtendremos la velocidad de marcha (suele ser de $162 \mathrm{Km} /$ hora cuando la movilización es masiva). Así pues, el caudal de manifestantes/hora en una avenida ancha (cuatro carriles) puede cuantificarse entre 15.000 y 20.000 asistentes, aunque todo ello depende de la distancia que exista entre las filas de manifestantes, los laterales, etc. Para esos recuentos de filas son útiles los aparatos manuales de contador (de viajeros) utilizado aquí para contar cabezas, filas o personas que forman el ancho del cortejo.

\subsection{Arcos de recuento}

Mencionamos aquí un sistema de recuento automático - experimental- denominado Station set up to count the protesters. Consiste en fijar una salida y una llegada del cortejo situando, en el tramo central del recorrido, tres arcos (metas volantes) que cuentan automáticamente con un sensor a los manifestantes que lo cruzan a su paso. Encima de ellos, unos paneles informativos indican el número de personas que han pasado.

El 21 de septiembre de 2002 se celebró en Londres la manifestación $L i$ berty and Livelhood, en defensa de la caza del zorro. Para algunos fue «la mayor manifestación de los últimos 150 años» ${ }^{12}$ (Efe). Procedentes de todo el Reino Unido rural, marcharon durante ocho horas desde Hyde Park hasta Whitehall para defender el tradicional estilo de vida del campo británico, que incluye la caza del zorro con perros. Para el evento no se escatimaron recursos. Se usó este sistema de recuento (ver Figura 5). Según esta experiencia, al evento asistieron 407.791 personas (a posteriori 400.000 según la policía londinense). El sistema es bastante preciso, pero costoso y por tanto fuera del alcance de muchas organizaciones. Además, ante tan apabullante exactitud, una vez obtenido el número de asistentes, nos encontramos nuevamente ante la difícil interpretación del significado de esa muchedumbre mensurable y cuantificable. Se recomienda en estos casos hacer una encuesta sociológica y posiblemente tomarla en cuenta.

\subsection{El cálculo de masas dinámicas: tiempo y espacio}

Pero normalmente no hace falta tanta tecnología para medir el respaldo de la protesta. En manifestaciones de tamaño intermedio (de menos de 5.000

${ }^{12}$ En la comparación, la prensa se remontó a 1834, en que un grupo de obreros, los «mártires de Tolpuddle», lideraron una masiva protesta por sus derechos sindicales. 


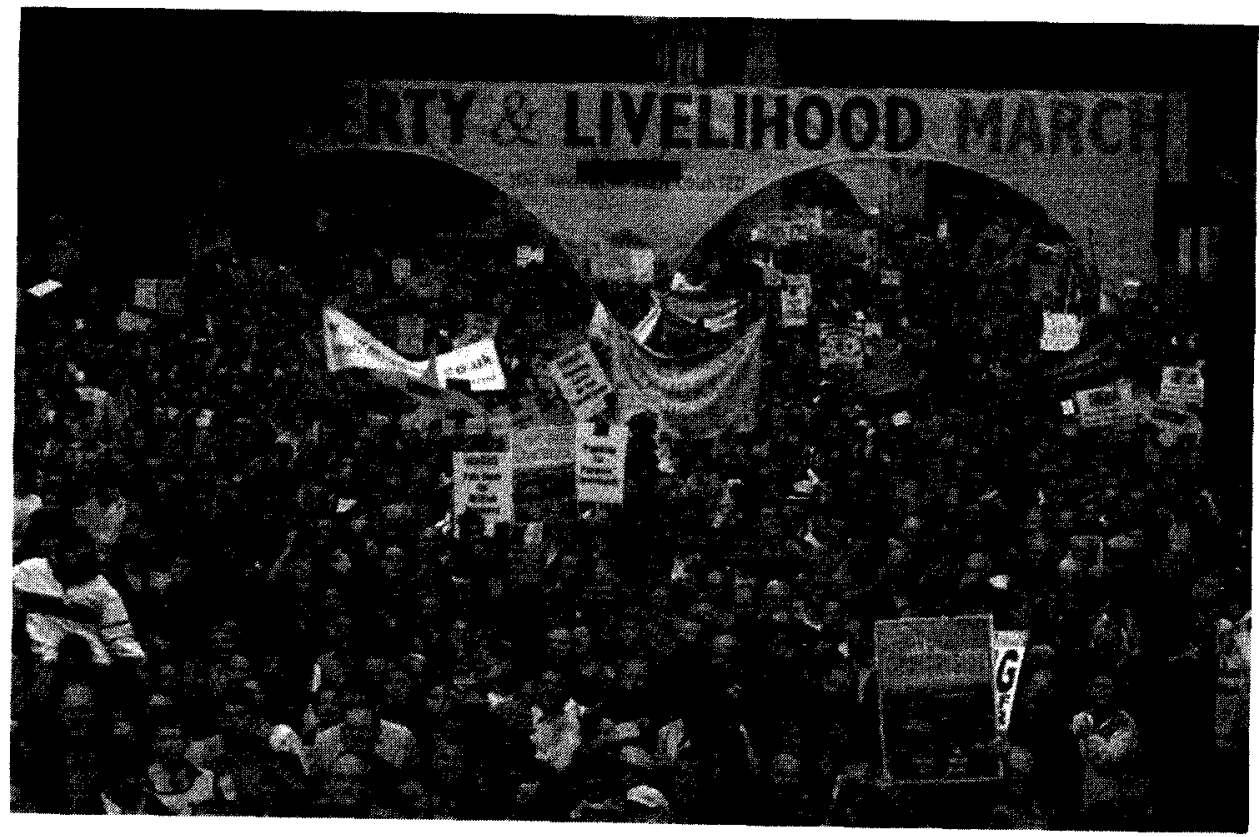

Figura 5. Station set up to count the protesters: el 21 de septiembre de 2002, manifestación Liberty and Livelhood, en defensa de la caza del zorro en Londres. Asisten 407.791 personas. (Agencias).

personas, por ejemplo), las mediciones pueden ser más objetivas. En todo caso, para valorar la dimensión de la reunión resulta crucial la elección del momento de máxima asistencia. Para ilustrarnos un poco más, en el siguiente ejemplo ofrecemos de forma visual tres supuestos de manifestación tipo (Gráfico 1).

Con ello veremos cuál es el momento idóneo para el recuento. En el caso A se trataría de una manifestación clásica, legal y sin incidentes. El punto óptimo para la correcta medición del aforo ( 1.500 asistentes) se situaría entre el momento II (desarrollo) y el III (final). Las cifras de asistencia variarán en función del momento en que el informe policial o la conexión de los periodistas se produzcan. El sesgo habitual es contarlos en I. En el caso B, se trataría de una manifestación convocada como tal (I), y que en pleno desarrollo (II) se ve truncada por un suceso disgregador y termina reagrupándose, o al menos intentándolo. La cifra de asistentes sería de 1.100 personas, y en ningún caso se trataría de 2 o 4 manifestaciones (confusión habitual en la Transición). En el caso C estamos ante una manifestación en forma de salto (ilegal) que constantemente reagrupa a los dispersados manifestantes. La correcta medición de los asistentes se situaría en el momento de su inicio (I). 
Estos parámetros son (o deberían) ser tenidos en cuenta en movilizaciones masivas, por parte de autoridades, periodistas, convocantes, y observadores. Los resultados muestran que con su utilización las fuentes se acercan más al número real de asistentes, pero no es tampoco exacto. Se impone la necesidad objetiva de obtener un recuento sobre el terreno, a pie de manifestación, realizado por un observador imparcial con la utilización de los recursos «técnicos» (mapa, podómetro, cámara de fotos, etc.) y humanos (varios equipos de dos personas) que hicieran falta en cada caso.

A) Tipo: $\quad$ M-M-M-.

Legalidad: Lc.

Sucesos: P.

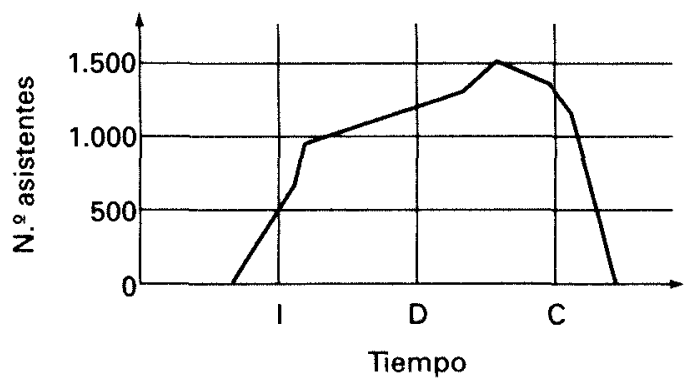

B) Tipo: $\quad$ M-S-M-

Legalidad: L/Ln.

Sucesos: I.

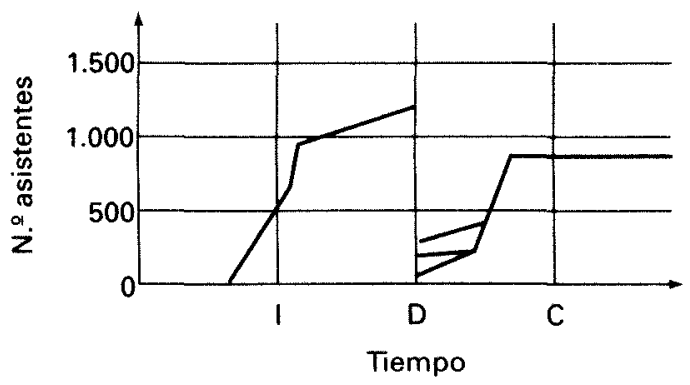

C) Tipo: S-S-S-.

Legalidad: I.

Sucesos: V.

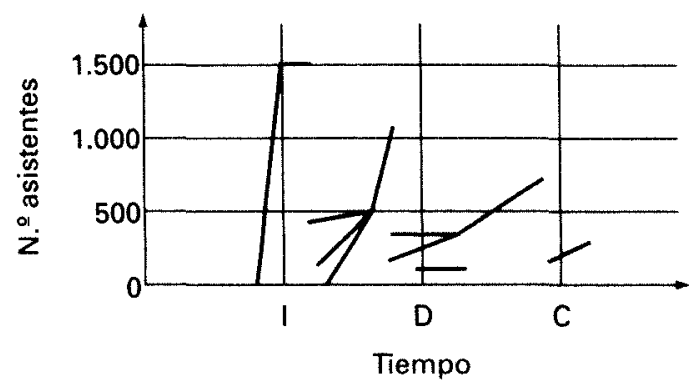

Gráfico 1. Cambios de adhesión durante la movilización. 


\subsection{Otras magnitudes: suciedad y violencia}

Desde mediados de los años 90, ante la imposibilidad de restringir las movilizaciones sociales a un «manifestódromo» por parte del alcalde de Madrid, Álvarez del Manzano, se impuso la práctica de «limpiar la protesta» de las calles. La limpieza viaria inmediata tras la manifestación como forma de acoso y ocultación de los mensajes que conlleva la protesta y con ello aparece una nueva magnitud que permite comparar las movilizaciones: según el peso de suciedad recogida por los servicios especiales de limpieza ${ }^{13}$.

Ciertamente las manifestaciones ciudadanas generan gran cantidad de pancartas, panfletos, etc. y en las reuniones duraderas, festivas o procedentes del resto del estado, se generan además abundantes restos de comida y botellas en la «toma de Madrid».

Aun así, de sus propias cifras podemos extraer algunas magnitudes interesantes o al menos curiosas: el 14 de julio de 1997 en la manifestación contra el terrorismo (M.A. Blanco): $30.000 \mathrm{~kg}$ de basura. En la manifestación del 22 de marzo de 2003 contra el inicio de la guerra se recogen más de $20.000 \mathrm{~kg}^{14}$. El 11 de marzo del 2001 en la marcha aragonesa contra el PHN: $20.000 \mathrm{~kg}$ de basura (empleándose 200 trabajadores y 37 vehículos). En la del 15 de febrero de 2003 contra la participación de España en la guerra de Irak participaron 200 trabajadores y 70 máquinas ${ }^{15}$; en la huelga del $20-\mathrm{J}$ de 2002 , al paso de la manifestación contra la reforma laboral se recogen $15.000 \mathrm{~kg}$. A estos ejemplos se podrían añadir otros, como los costes de limpieza de las 200 chabolas del «Campamento de la esperanza» (2001) de los trabajadores de Sintel que duró 187 días ${ }^{16}$. Si vemos que los costes ecológicos y económicos de la protesta son altos, otras reuniones públicas de carácter festivo (limpieza «especial nochevieja en la puerta del Sol» (2000/2001): $25.000 \mathrm{~kg}$ ), deportivo (maratón popular: $50.000 \mathrm{~kg}$ de botellas de plástico y publicidad, Título de Liga Real Madrid-2003: $52.350 \mathrm{~kg}$ y 171 operarios, Vuelta Ciclista, etc.) o institucional (Boda Real-2004: $9.000 \mathrm{~kg}$, Desfiles FFAA, etc.), no lo son menos.

13 La recogida de kilos de basura por la contrata del Ayuntamiento de Madrid, SELUR (Servicio de Limpieza Urgente), que se produce de forma inmediata tras las reuniones multitudinarias, y su pesaje, junto a la delimitación de superficie de $\mathrm{m} 2$ de pintadas o pegatinas limpiadas, justificaba el exagerado despliegue de medios humanos y materiales así como el abultado gasto de esta contrata. Actualmente sigue en curso una investigación judicial, por el excesivo costo de esos despliegues.

${ }_{14}$ Además de multiples destrozos: pintadas y serigraffitis $\left(4.500 \mathrm{~m}^{2}\right)$, cabinas, cubos de basura quemados, adoquines, botellas rotas, restos de hogueras, coches cruzados. Según el entonces ministro del Interior M. A. Aceves, los gastos ascendieron a $300.000 €$, más $1.200 .000 €$ de mobiliario urbano.

${ }^{15}$ Según el Alcalde, los gastos de esta manifestación y la del 23 de febrero 2003 contra la catástrofe del Prestige, sumó un gasto por destrozos (parterres, mobiliario) de $288.000 €$ $(=47.919 .168$ ptas $)$.

${ }^{16}$ El Ayuntamiento gastó 100.000.000 ptas para retirar trastos, arreglar los desperfectos, proceder a la desinfección. El despliegue fue de 310 barrenderos y 78 vehículos, que en 32 horas rehabilitaron la zona. 
Según los datos del SELUR cruzados con los nuestros de asistencia a movilizaciones podemos concluir (el dato poco trascendente) que un manifestante genera entre 20 y 200 gr. de desperdicio durante su protesta, en función de su comportamiento y del contexto y lugar del evento.

Otras cifras extrábles del fenómeno manifestación, y más polémicas si cabe, se obtienen de los balances de la violencia. Durante la Transición Política se producían detenciones masivas, heridos e incluso muertes. Ello era un indicador que permitía comparar la lucha y la represión en términos de violencia. En los 90, la llamada kale borroka ha producido también un extenso balance de violencia. Destrozos, desperfectos y amenazas se han sucedido y cuantificado. Aun siendo el de la violencia un fenómeno minoritario, hablaremos aqui no ya de los costes en dispositivos de prevención o de los desperfectos materiales sino de los costes humanos. Así por ejemplo, y hoy por hoy, seguimos sin conocer el número de muertos en el transcurso de protestas en la calle durante el franquismo y la transición política. Diversas instituciones impulsan en la actualidad iniciativas que nos ayuden a conocer qué pasó, y el balance de la represión durante el franquismo. La labor de investigación no es fácil, si bien parece que hoy sería conveniente en aras del conocimiento (recuperación de la memoria histórica) y de las posibles indemnizaciones o resarcimientos morales. Según nuestra investigación y tras los filtros de silencios y rumores de unas fuentes u otras (oficiales y organizadores), entre el periodo 1970 y 1981 fallecen en todo el Estado al menos 80 personas en el transcurso de manifestaciones en la calle (yendo, participando o retirándose del evento). Aun faltando casos (oscurantismo de los años setenta) y siendo una cifra relativamente baja, el dato no es despreciable, y una vez más, además de una cifra, detrás existen nombres y apellidos ${ }^{17}$ ( 72 varones y 8 mujeres) y un cúmulo de circunstancias dramáticas. Las víctimas son

${ }^{17}$ Cristóbal, Antonio - Sánchez, Manuel - Huertas, Antonio - Pérez Jáuregui, J.R.- Patiño Toledo, Pedro - Ruiz Villalba - Fuertes, Juan M. ${ }^{a}$ - Rey Fernández, Amador - Niebla García, Daniel Fernández Márquez, Manuel - Fernández Gutiérrez, Juan Antonio - Urritz Geli, Carlos - Roldán Zafra, Miguel - Montenegro, Manuel - Arriola, Luis - Navarro, Diego - Rodríguez Román, Emilio García Ripalda, Jesús - Antón Ferrero, Vicente - Del Valle Pérez, Teófilo - Martínez Ocio, Pedro M. $^{a}$ - Barroso Chaparro, Romualdo - Aznar Clemente, Francisco - Castillo, José - Pereda Moral, Bienvenido - Rodrígo Kafo, Juan Gabriel - Ferrer, Vicente Antonio - Garmendia, Manuel M. - García Pellejero, Ricardo - Jiménez Santos, Aniano - Menchaca, Begoña (Nomi) - Zabala Erasun, Jesús María - González Martínez, Carlos - Almazán Luna, Ángel - Casabany, José Vicente - Iglesias Sánchez, Juan M. ${ }^{a}$ - Ruiz García, Arturo - Nájera Julián, M. ${ }^{a}$ Luz - Aristizábal, José Luis - Zusperregui Aldaco, Isidro - Gómez Jáuregui, Rafael - Cano Pérez, José Luis - Santamaría Miquelena, Luis - Caño Ibáñez, Clemente - Marichalar, Gregorio - Peralta Sánchez, Roque - Freicher Solana, Carlos Gustavo - Sánchez García, M. ${ }^{a}$ Josefa - García Caparros, José Manuel - Fernández Quesada, Javier - Rodríguez Ledesma, Francisco - Egea Gómez, Ramón - Montoro Barajas, Diego - Bravo Bejarana, Bernabé - López Masip, José - Parcero Rodríguez, Elvira - Echeverri Cheverri, Juan - Carrasco Alejandro, M. ${ }^{\mathrm{a}}$ Luisa - Rodríguez, Germán - Barandiaran Urkola, Joseba - Muñoz Bustillo, Gustavo A. - Oyola Medina, Manuel - Gallego, Ursino - Del Estal, Gladys - González Ramírez, Valentín - Sánchez, Teodora - Fernández Castro, Emilio - Quijera Zelaraín, José Ignacio - Martínez, Valeriano - Montañés Gil, José Luis - Martínez Menéndez, Emilio - Cuervo Calvo, Vicente - Pajuelo, Arturo - García Pérez, Juan Carlos - Begoña, Ramón - Sánchez Ojeda, Belén M. ${ }^{a}$ - Mendoza Lavera, Joaquín - Morales, M. ${ }^{a}$ Asensio.

EMPIRIA. Revista de Metodología de Ciencias Sociales. N. ${ }^{\circ}$, enero-junio, 2005, pp. 171-208. ISSN: $1139-5737$ 
manifestantes o transeúntes y en dos casos, los fallecidos son miembros de las Fuerzas de Orden Público ${ }^{18}$.

\subsection{La intuición y la costumbre}

Con un dilatado espacio temporal de análisis, y salvo excepciones, podemos afirmar que los escenarios del conflicto, en una capital de Estado como Madrid, son tan repetitivos como los conflictos mismos. En otras palabras, los recorridos, los temas de reivindicación y las capacidades de convocatoria son relativamente estables. Ello ocurre también en otros escenarios urbanos como es el caso de Barcelona (Delgado, Horta, Monnet, 2003). Por ello, desde una buena posición se pueden hacer comparaciones (más o menos odiosas) de mayor o menor asistencia. Además, como luego veremos, la mayoría de las reuniones no supera los 500 asistentes. Estos cálculos rápidos e intuiciones (y por tanto usos no científicos) tienen rango de técnicas intuitivas o funcionales. Sobre el terreno, algunos policías, periodistas y organizadores veteranos han adquirido esta capacidad (más o menos eficaz) de cálculo ${ }^{19}$. En el caso de las manifestaciones, aún pareciendo todas iguales tienen peculiaridades distintas.

\section{SESGOS, ESPEJISMOS Y SIGNIFICADOS}

Veamos seguidamente «la magia de las cifras», y por tanto las limitaciones y sesgos que dificultan la propia interpretación de las cifras. Con ello entramos en los significados de la movilización.

\subsection{Minoría versus mayoría}

Como señala acertadamente Norbert Lechner «la relación mayoría/minoría depende de la definición del entorno social. La mayoría numérica de una sociedad puede aparecer en determinada situación como minoría formal. A la inversa, la minoría numérica puede aparecer en determinadas condiciones como mayoría formal» (Lechner, 1986: 80). Es erróneo pensar que los condicionantes para ma-

${ }_{18}$ Entre los fallecidos se conocen dos casos de víctimas de las FOP. El 1. ${ }^{\circ}$ de mayo de 1973 , Juan Antonio Fernández, miembro de la Brigada Político-Social, fue apuñalado en Madrid por miembros del FRAP (extrema-izquierda). El 17 de mayo de 1978, el Subteniente de la Guardia Civil Juan Echeverri, apuñalado en Pamplona por manifestantes nacionalistas, y murió días más tarde.

19 Algunos antecedentes de intuiciones - no científicas - las tenemos en la propia cultura rural. Así por ejemplo, muchos pastores no saben sumar, en cambio sí saben reunir rebaños. Hace miles de años a uno de ellos se le ocurrió juntar guijarros por cada oveja que salía del corral por la mañana. Al atardecer, procedía a la misma operación, pero a la inversa. Computaba así su rebaño. Hoy en día, y según confiesan algunos, de faltarles una oveja en el rebaño, lo detectan rápidamente, por la propia forma del rebaño, como si las demás delatasen su ausencia. 
nifestarse son iguales, y por tanto comparables, en todos los individuos y en todos los casos. Además de los condicionantes climáticos, existe facilitación o coerción a la movilización. En algunas localidades del País Vasco, por ejemplo, se viven situaciones contradictorias de este tipo. Un ejemplo de ello lo tenemos en la convocatoria del 25 de septiembre de 2002 en Leiza (Navarra), en donde se pueden contar en la foto de prensa a 57 asistentes, en repulsa de la muerte del guardia civil Juan C. Beiro tras una pancarta con el texto «Leiza y Navarra por la libertad», mientras que el pie de página de El Mundo habla de 40 participantes (no debió de contar a los escoltas). En cualquier caso, sean finalmente 57 o 40 los concentrados lo importante a tener en cuenta de ese acto es que se producía en una localidad de 3.000 habitantes y con una corporación municipal, por entonces, de Batasuna, pues en contextos de miedo o coacción, cincuenta personas pueden representar a muchas más. En estos casos de constricción de libertades se ha de valorar la calidad de la participación frente a la cantidad de participantes. No sabemos, a cuantos otros representan los allí concentrados.

Toda movilización no deja de ser un botón de muestra del descontento, pero ciertamente son muchísimos más los ciudadanos que no ejercen el derecho de reunión (entre el 70\% y el $80 \%$ de los ciudadanos, según el CIS). Sin duda existe también satisfacción y contento o al menos conformismo suficiente en muchos sectores sociales que se sienten ajenos a la acción colectiva. Así por ejemplo, en el 2002, la entonces ministra de Educación Pilar del Castillo restó credibilidad a la numerosa y reiterada protesta estudiantil y sindical contra la LOU afirmando que «son muchos más los ciudadanos que no salen a la calle y por tanto a favor de la ley». Esa frase tiene trampa. Es cierto que cualquier tema que movilice a mucha gente no implica que toda la sociedad esté de acuerdo. Por ejemplo, ¿hubiera sido posible una masiva movilización a favor de la ley? En condiciones normales parece que no. Un espejismo de ese tipo lo tenemos en el tema de la campaña Referéndum OTAN de 1986 que mostró una masiva movilización en contra en la calle (sin «manifestaciones» a favor), mientras que en las urnas el $52 \%$ de los votantes estaba a favor de la Alianza Atlántica, con condiciones (Ver Adell, 1996). Este efecto competitivo de la movilización se produce también entre autonomías. En la movilización pro PHN (apoyada por País Valenciano y Murcia) y anti PHN (Aragón y Cataluña) tenemos otro efecto similar. Se presupone hostil o al menos incómodo manifestarse a favor del PHN en Aragón, o en contra en Murcia. Ello convierte en demagógica la frase de la ex ministra, a la vez que cualquier interpretación científica a través de la comparación numérica no resulta explicativa sin el análisis, en un segundo momento, de estos condicionantes. En el caso de la LOU, la afirmación de la ex ministra demuestra que la mayoría de la sociedad aún no quería un cambio de gobierno pero oculta que la gran mayoría de la comunidad educativa estaba en contra de su política.

Por tanto el calificativo de muchos o pocos manifestantes a una convocatoria no viene dado por el número absoluto y objetivo de asistentes, sino más bien, y eso es importante, en relación con el colectivo (de clase, ideológico, sectorial, afectado) que dicen representar. Por ejemplo, 100 trabajadores de una empresa 
concentrados son muchos y mayoría si su plantilla es de 120 , pero son pocos si el colectivo al que representan son 5.000 empleados, o a «la clase obrera» en general. Concluimos, que una mera cifra de manifestantes no es necesariamente representativa si no tenemos en cuenta los condicionantes que la determinan y al colectivo que dicen representar.

\subsection{Guerra de cifras: creer o no creer}

Por comodidad, carácter, convicción, fiabilidad o autoridad, la ciudadanía tiende sistemáticamente a creer en una sola fuente. En unos casos, a las cifras oficiales, de las que se presupone técnica, autoridad y poder. En otros a los organizadores (por su justa causa, intentos de silenciamiento, etc.). Existe un tercer colectivo, de ciudadanos neutros y descreídos de ambas posturas, que aplican la media. A ello contribuyen incluso los periódicos que informan; como afirma $\mathrm{Ar}$ cadi Espada, «los periódicos, en el exponente más caricaturesco de lo que llaman las versiones de los hechos, suelen comenzar sus crónicas sobre las manifestaciones diciendo que cincuenta mil según los organizadores y veinticinco mil según la policía desfilaron ayer. Para los lectores más exigentes el mensaje es nítido: saque usted la media» (Espada, 2003: 140).

La «sabiduría popular» tiende a hacer la media entre las fuentes, lo cual presupondría una objetividad de las mismas que, aun difiriendo, tendrían cifras cercanas. Esto no suele ser así. A veces las fuentes no abundan en el dato o las cifras, mal calculadas en muchos casos, son erróneas. Generalmente son muy dispares por el contenido partidista, relativo y subjetivo del éxito o fracaso que entraña una convocatoria. Así pues no se debería calcular la media sistemática entre fuentes, y menos aún cuando disponemos de tan sólo dos, tan opuestas, habitualmente, como son la oficial y la de los organizadores. Algunos autores incurren en esta intuición sesgada como en los estudios de Vázquez y Plaza (1985).

Tratando de indagar en el fenómeno, y para establecer los márgenes de error que ofrecen las distintas versiones, se observa alguna tendencia. Si de las movilizaciones aquí estudiadas seleccionamos una muestra de 190 casos en los que se aportan cifras de asistencia de organizadores y de Delegación del Gobierno, podemos realizar recuentos parciales, de las dos fuentes y añadir una tercera, la cifra de asistentes - operativa-asignada finalmente en el estudio. Entre los tres recuentos observamos importantes discrepancias.

El Gráfico 2 nos ilustrará con un ejemplo. Se muestra aquí una hipotética manifestación con una asistencia de 100 personas según la cuantificación aplicada en nuestro estudio.

Esa misma movilización hubiera reunido a 33 personas según fuentes oficiales o a 330 manifestantes según organizadores. Obviamente se trata de un caso hipotético de carácter explicativo. Las cifras de los medios de comunicación oscilarían entre las 50 y 150 personas. Cabría preguntarse si las cifras mal calculadas o las cifras politizadas son tan sólo eso, o sus propios emisores caen lue- 


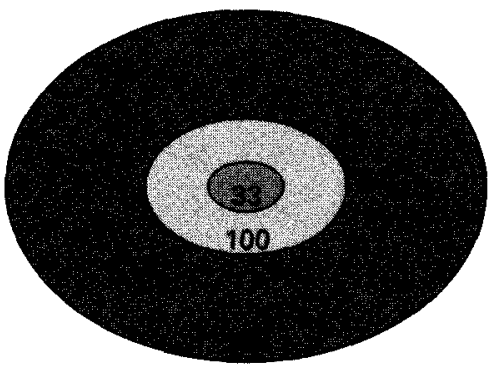

Cifra oficial $\square$ Estudio Convocantes

Gráfico 2. Cifras de asistentes a la concentración (segun fuentes).

go en falsos análisis de la realidad. Veamos un ejemplo típico. Si una organización ofrece la cifra de 1.000 asistentes de una reunión de un centenar (fácilmente contable y por tanto cuantificable), con qué acierto en sus posteriores acciones habrá valorado una cifra u otra (éxito/fracaso).

En muchas organizaciones, las cifras de los organizadores se imponen sobre las militancias como si de un dogma se tratara. De igual modo, y en el polo opuesto, un recuento ideologizado por parte del poder puede menospreciar la capacidad de convocatoria de los organizadores, y por tanto, dejar de prever acontecimientos posteriores. Como vemos, la guerra de cifras es más corriente en aglomeraciones que reúnen a grandes multitudes ${ }^{20}$.

Posiblemente las cifras aportadas por la policía son algo más rigurosas, pero, al menos en el caso español, la cifra oficial resultante suele minimizar el respaldo a las protestas. Por el contrario la «cifra política» de las macro-movilizaciones de adhesión resulta habitualmente abultada. A ello se añaden múltiples errores técnicos o de percepción.

Hemos visto las diferencias en la medición de asistentes que existen en una muestra de pequeños eventos. Las distorsiones en las cifras totales también existen. Las propias cifras oficiales de datos anuales sobre el ejercicio del derecho de reunión y manifestación son contradictorias e incluso sorprendentes. En diciembre de 2004, la Comunidad de Madrid, citando a la Delegación de Gobierno, facilitó los datos de manifestaciones y asistentes en las reuniones celebradas en la comunidad autónoma durante el año 2003. Según estos, se celebraron finalmente 915 movilizaciones a las que asistieron 3.954 .204 personas.

En el Gráfico 3 presentamos, para el periodo 1993-2003, los datos oficiales de movilizaciones y asistentes para toda la CAM. Igualmente se exponen los da-

${ }^{20}$ En actos como la misa que celebró el Papa en la Pza. de Colón de Madrid (16-06-1993) se observan también algunas disfunciones en las cifras de asistentes. El helicóptero de la Policía cifró en 800.000 el número de participantes, mientras que el Alcalde dio la cifra de un millón trescientos mil $\left(10 \times \mathrm{m}^{2} ! !\right)$. Por su parte, El País cifró en 366.160 el número de congregados $\left(91.540 \mathrm{~m}^{2} \times 4\right)$. 


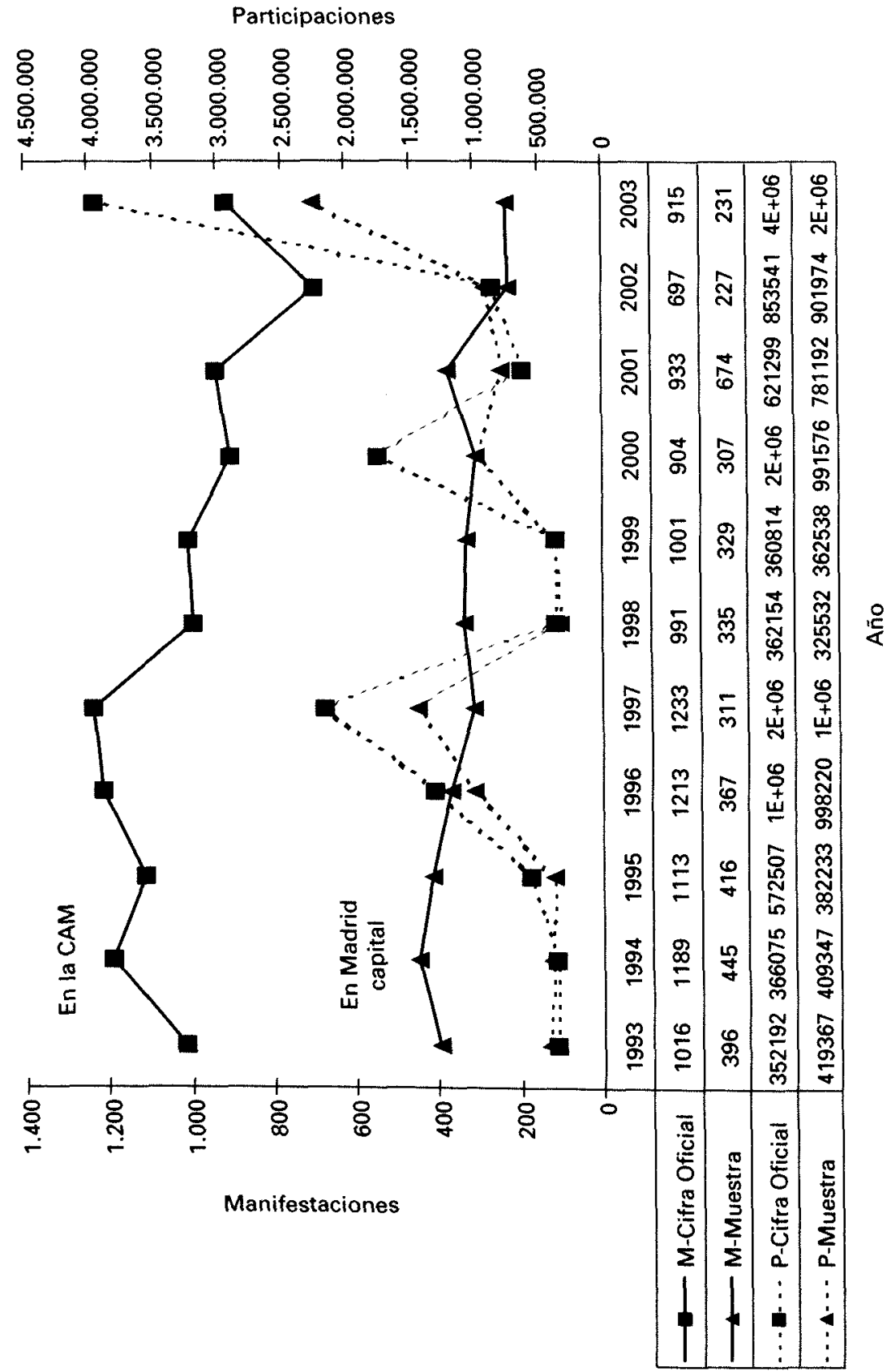

Gráfico 3. Manifestaciones en Madrid (1993-2003) según fuentes. 
tos referentes a la muestra estudiada (en este caso sólo de la capital, Madrid-21 distritos). Los datos de asistencia oficiales suelen ser más bajos que los de la muestra a excepción de los años 1996, 1997, 2000 y 2003. Podemos interpretar que ello se debe a las abultadas cifras de asistencia ofrecidas por la Delegación de Gobierno en las movilizaciones contra el terrorismo de 1996 (Tomás y Valiente), 1997 (Miguel Ángel Blanco), 2000 (Pedro Antonio Blanco), ya reseñadas en otros apartados de este artículo. La paradoja se produce en el año 2003 (movilizaciones: Prestige, contra la guerra, gays, etc...). Las cifras oficiales totales para dicho año presentan un repunte de la movilización, superando en más de millón y medio la cifra de asistentes de nuestra muestra. Tras una revisión pormenorizada de la conflictividad de dicho año, no encontramos a esos manifestantes por ninguna parte. Aún pensando en la existencia de una inusitada movilización regional (entorno al $18 \%$ de las manifestaciones extra-capitalinas). A excepción de la manifestación del 28 de junio por el orgullo gay, en donde sorprendentemente se reconoce a más de medio millón de asistentes, las otras manifestaciones registran cifras oficiales a la baja (característica habitual y en mayor medida de la etapa 2000-2003, con F. J. Ansuátegui al frente de la Delegación de Gobierno).

Así por ejemplo en las tres principales manifestaciones contra la guerra ( 15 febrero, 15 de marzo y 22 de marzo de 2003), nuestros datos arrojan un total de 1.450.000 asistentes, mientras que las cifras oficiales (en su momento) reconocen tan sólo a 800.000 . A tenor de los organizadores, los participantes en las mismas fueron más de tres millones quinientos mil. Por tanto las recientes cifras oficiales para el año 2003, son a todas luces imposibles, y el error podría estar simplemente en una errata, en la inclusión de los asistentes a las misas del Papa (misa con los jóvenes en aeródromo de Cuatro Vientos y plaza de Colón), o en un giro político reinterpretativo e intencionado de dicho año.

\subsection{Contenido y continente}

No hay que olvidar tampoco que gran parte de la demostración de fuerza que supone la masiva asistencia en una convocatoria clásica (de masas), no sólo dirige una demanda al destinatario explícito (poder, adversario, opinión pública), sino que además emite un mensaje de cohesión para el destinatario implícito (militancias, asistentes, convencidos, etc.). En estos casos, la elección del escenario físico del acto es crucial. Generalmente el trayecto, lugar y espacio físico de la convocatoria se tiene meticulosamente en cuenta por los organizadores, para dar suficiente, pero justa, cabida a los asistentes. Se busca el lleno total. Ello se observa por ejemplo en la elección de una plaza con un tamaño suficiente para llenarla, o al menos para que esté medio llena (y no medio vacía!). Los grandes escenarios (líderes), torretas y aparcamientos (TV y radio) y dispositivos de seguridad de cabecera o recorrido (PN, SAMUR, etc.) restan amplios espacios a los concentrados (manifestación 12 de marzo 2004, Boda M-2004, etc..) y por tanto debe tenerse en cuenta a 
la hora de medir la asistencia real. Igualmente las calles adyacentes suelen reunir en estos casos a mucha gente moviéndose o colapsada, según los casos.

Así por ejemplo, según nuestro estudio la media del aforo de algunas plazas de Madrid vendría dada por el tamaño de las manifestaciones que se concentran en ellas o de las que empiezan, transcurren o finalizan en dichos lugares. Según el Cuadro 1 la media de asistentes en el periodo 1975/2002 para distintas plazas y calles sería:

Cuadro 1

Aforos urbanos (ejemplos)

\begin{tabular}{|l|r|r|r|r|}
\hline \multicolumn{1}{|c|}{ Escenario urbano } & Media & Mínimo & Máximo & $\begin{array}{c}\text { N. casos } \\
\text { muestra }\end{array}$ \\
\hline Puerta del Sol & 2.350 & 21 & 200.000 & 522 \\
Plaza de la Villa & 490 & 21 & 8.000 & 351 \\
Plaza Mayor & 3.300 & 25 & 70.000 & 85 \\
Plaza de Oriente & 65.000 & 30 & 350.000 & 35 \\
Plaza J. Benavente & 2.900 & 50 & 20.000 & 44 \\
Paseo de la Castellana & 5.600 & 21 & 450.000 & 270 \\
Plaza de Cibeles & 8.500 & 25 & 600.000 & 200 \\
Plaza de Colón & 30.400 & 30 & 1.100 .000 & 125 \\
\hline
\end{tabular}

Así por ejemplo el espacio de la Puerta del Sol, por lo que representa (centro-ciudad, estado-km 0, DGS, Comunidad Autónoma de Madrid, etc.), resulta ser uno de los espacios con más convocatorias celebradas ( 522 casos reseñados en la muestra). Además no se cuentan aquí tampoco las reuniones de menos de 21 personas (muy numerosas). La media de asistentes estaría en torno a los 2.350 manifestantes si bien hay que puntualizar que la mayoría de convocatorias allí celebradas estaría apoyada por 300 o 500 asistentes. El máximo de 200.000 no implica que quepan en la plaza (aforo de 25.000 a 40.000 personas), sino en este periodo y lugar al menos dos convocatorias con esa cifra estimativa concluía allí (llenando por tanto otras calles adyacentes) ${ }^{21}$. En comparación la Plaza de Oriente se presenta como un lugar poco autorizado y hostil a las convocatorias (desangelado para el pueblo), a excepción de las masivas movilizaciones del Gobierno y la ultraderecha en los años setenta (cúspide en 1979). Por ello registra una alta media (orientativa) por convocatoria. Se exponen en el cuadro algunos ejemplos más.

${ }^{21}$ En los dos casos el recorrido era Puerta de Alcalá/Cibeles/calle Alcalá/Puerta del Sol. Nos referimos a la manifestación del orgullo gay ( 29 junio) y a la manifestación sindical contra el decretazo ( 5 octubre), ambas en el 2002. 


\subsection{Ritualización de la protesta: de la lucha a la institucionalización}

Cuando hablamos de cifras no se nos escapa que el ambiente en que se desarrolla la convocatoria es determinante también a la hora de valorar la fría cifra de ciudadanos anónimos que deciden (a pesar de los «costes» Olson) reunirse. Reunirse ¿para qué? para luchar, incluso violentamente, y sufrir el alto coste de la represión, para expresar de forma festiva un cambio de valores, para solidarizarse?, ¿porque los sindicatos dicen que ahora toca manifestarse?, ¿como expresión pacífica, simbólica y constitucional siendo conscientes de la dudosa eficacia de está práctica?

Pongamos algunos ejemplos. Los manifestantes, sea cualquiera su cifra y demanda, tienen deseos, sentimientos de injusticia, y en muchos casos necesidades urgentes que solucionar. En definitiva, necesitan expresarse y ser oídos (input en agenda del poder capaz de resolverlo). Para ello, las organizaciones diseñan tácticas y estrategias para distintas fases de la presión (campañas de movilización). El repertorio de las formas de acción es amplio, tanto en el ámbito de la memoria colectiva como en las capacidades de creatividad social. La elección de un ambiente pacífico o de violencia viene diseñado o esperado por los actores de la protesta (organizadores, participantes, fuerzas del orden). Pero a veces las expectativas entre estos son distintas o enfrentadas. Además, sucesos inesperados pueden alterar una reunión, pasando de la fiesta a la violencia. En muchos casos, la violencia minoritaria de unos puede ser ahogada por una multitud pacífica. $\mathrm{La}$ expectativa de violencias reduce sensiblemente el número de asistentes e incide en el perfil de los que finalmente deciden asistir.

¿Cómo es posible, por ejemplo, garantizar un ambiente pacífico en una convocatoria con cierta crispación en el ambiente y la complejidad de las múltiples historias de vida que tienen sus participantes? Las organizaciones son las que garantizan el acto (servicio de orden) cohesionando a los asistentes. En un segundo círculo las fuerzas del orden protegen o en su caso disuelven el acto. Pero qué ocurre cuando la adscripción partidista de los congregados al evento es etérea, temporal, o débilmente estructurada por parte de las organizaciones? El progresivo debilitamiento de los partidos políticos y sindicatos, el auge de los aún desestructurados movimientos sociales y el creciente individualismo posmoderno vuelve más complejo «el control del ambiente». Aun así, los individuos buscan códigos de cohesión entre sí. Resucitada la biosociología, los estudios de Noelle-Newman sobre los bancos de peces nos acercan también al fenómeno de los comportamientos «de masas» e incluso del liderazgo en un sorprendente experimento. «En el interior del banco de peces no hay estructura alguna, no hay jefes ni subordinados...(pero)... hay algunas formas sencillas de comunicación. Cuando uno de ellos percibe el peligro y huye, transmite su sensación a los demás» (Noelle-Mewmann, 1995: 134135). En su experimento, convirtieron a una carpa en líder, anulando su espíritu gregario gracias a una intervención en su cerebro. Cada movimiento que hacía la carpa era imitado por el resto. Observó a su vez, que el movimiento de 
las otras carpas no afectaba a la carpa intervenida. Con ello se convierte en un punto fijo exógeno.

Ciertamente, y cada vez más, en concentraciones masivas, los reunidos no se contentan con seguir un itinerario y quedarse inmovilizados detrás de una pancarta partidista. Muy al contrario, los asistentes desarrollan técnicas de movilidad autónomas y cogen atajos, calles adyacentes, etc. para poder llegar al lugar, protestar y retirarse con la mayor economía de esfuerzo. La cabecera «oficial» por motivos de seguridad actúa igualmente como «gorrón o jinete solitario». Ello desluce la manifestación clásica. En estos casos la masa se convierte en un fluido y es capaz de crear incluso itinerarios propios no regulados. Así lo muestran los estudios de Dirk Helbing en la Universidad de Stuttgart (Helbing et alt., 1997). Aplica modelos matemáticos a la simulación de los caminos utilizados por los transeúntes en una ciudad o en el diseño de un parque. Ello revela la rigidez de algunos diseños urbanos (pasos de peatones, sendas, falta de bancos para sentarse, etc.) y cómo son transgredidos una y otra vez por originales peatones que buscan atajos para sortear barreras artifiales poco funcionales. En la movilización, los asistentes se apropian de la calle (símbolo de la soberanía popular) sorteando cordones policiales, vallas, setos, coches aparcados, mobiliario urbano. Lógicamente estos usos, amparados en la masividad de la asistencia, van moldeando los espacios de una ciudad y por tanto los escenarios del conflicto. Esas dinámicas hacen que el observador tenga que tener en cuenta, la movilidad de los «manifestantes no adscritos» y curiosos.

Por su parte, Mark Granovetter aporta —en su modelo matemático (1990)la explicación de cómo se forma un comportamiento colectivo en una población de individuos racionales de los que cada uno se enfrenta a una elección binaria: por ejemplo, unirse o no a un motín; adoptar o no una innovación o una opinión; darse o no darse a la fuga ante el peligro; creer o no un rumor; etc. Ello nos recuerda una vez más que la masa no es sólo la suma de individuos, sino que la interacción que se genera entre ellos es importantísima. Cada individuo es racional en la medida en que sopesa el coste y las ventajas de una decisión positiva, pero se supone que estas últimas dependen del número de los que, por otra parte, toman la misma decisión. Existen por tanto umbrales individualizados en el comportamiento. Eso vuelve a plantear, por ejemplo, que el poder de atracción de una opinión crece con el número de individuos que la comparten. Un individuo no se unirá a un motín mas que si la proporción de los que ya se han unido es igual o superior al umbral que lo caracteriza. Es como si la mitad más uno de los asistentes cambiara de humor y se inclinara la balanza hacia un tipo de incidente o decisión. En definitiva explica «el contagio» entre los individuos, pero en parámetros calculables y racionales, y no como mera imitación animal, como se formulaba hasta principios del siglo XX. «Los rápidos cambios de opinión y de humor de las masas, en tiempos de revolución, proceden, no ya de las flojezas o de la movilidad de la psyque humana, sino, más bien, de su conservadurismo» (Moscovici, 1981: 157). Las masas se cohesionan o disuelven una y otra vez, pero sin dirección. Como afirma Jean Pierre Dupuy, refiriéndose a Granovetter, 
«si la sociología cuantitativa lleva a buen término su proyecto, quizá podrá decirse que la psicología de masas se convertirá en una rama de la física de los sistemas desordenados» (Dupuy, 1999: 113).

\subsection{No todas las manifestaciones son iguales}

Sería ingenuo pensar que todos los colectivos o temas tienen las mismas opciones para expresarse. Existen, además, condicionantes favorables y desfavorables de la movilización (facilitadores o coactivos, que diría Charles Tilly, desde la EOP) que inciden en una mayor o menor participación en la movilización. Estos condicionantes no son determinantes y muchos resultan imprevisibles, ya que obviamente la amplitud del colectivo afectado y la justicia de su demanda, junto a la credibilidad de los convocantes pesan aún más. De nuestras observaciones, entresacamos algunos factores:

\section{Cuadro 2}

Factores de la participación

\begin{tabular}{|c|c|}
\hline $\begin{array}{c}\text { Factores facilitadores de mayor } \\
\text { participación }\end{array}$ & Factores desmovilizadores \\
\hline $\begin{array}{l}\text { - Convocatoria anticipada. } \\
\text { - Anuncios previos en prensa, radio e } \\
\text { incluso televisión. } \\
\text { - Facilitación de tarima, sonido, retre- } \\
\text { tes, Samur, etc. } \\
\text { - Reforzamiento de transporte público } \\
\text { de acceso y desalojo del evento y } \\
\text { cortes de tráfico. } \\
\text { - Anuncio y realización de cortes de } \\
\text { tráfico preventivos (en tiempo y dis- } \\
\text { tancia). } \\
\text { - Amplio despliegue informativo en } \\
\text { directo y diferido sobre el evento. } \\
\text { - Tiempo agradable. }\end{array}$ & $\begin{array}{l}\text { - Obstaculización burocrática: recorri- } \\
\text { do, día, duración, lugar, etc. } \\
\text { - Obligación de circular por la acera. } \\
\text { - Silenciamiento e incluso confusión } \\
\text { en torno a la convocatoria. } \\
\text { - Anuncio de posibles incidentes. } \\
\text { - Acoso del servicio de limpieza mu- } \\
\text { nicipal. } \\
\text { - Falta de previsión en servicios públi- } \\
\text { cos. } \\
\text { - Silenciamiento o subestimación del } \\
\text { evento. } \\
\text { - Eventos deportivos o culturales a la } \\
\text { misma hora. } \\
\text { - Frío, lluvia o calor excesivo. }\end{array}$ \\
\hline
\end{tabular}

Por tanto las mayorías naturales que se expresan a favor o en contra, en igualdad de condiciones, no existen en ningún contexto, ya que se constatan numerosos condicionantes directamente facilitadores o coercitivos de la participación. 


\section{EL MILlón SALE A LA CALlE...}

Igual que un montón de monedas forman un tesoro, un millón de personas que sale a la calle supone un capital muy preciado para la colectividad. Como afirma Canetti, «todas las masas que se constituyen en tiempos de inflación $-\mathrm{y}$ es precisamente entonces cuando se constituye por montones-, están bajo la presión del millón devaluado. Tan poco como vale uno solo, así de poco vale entonces unido a los demás. Cuando los millones trepan, todo un pueblo de millones se convierte en nada» (Canetti, 1960: 183). Esta inflación, en el contexto de la movilización de legitimación, crea una dinámica de récords, que obliga a los promotores a intentar superar siempre la cifra máxima anterior. Un primer error o manipulación degenera, con el tiempo, en constantes reajustes o, peor aún, en una gran mentira, «tipo 1984 -Orwell» ${ }^{22}$, de la «historia inventada».

A este respecto, Grijelmo opina que «durante el franquismo, las concentraciones de apoyo al dictador que se celebraban en la plaza de Oriente reunían a "un millón de españoles". Con la salida de El País, los ciudadanos pudieron saber, merced a un curioso reportaje de ese diario, que en tal plaza no caben más de 300.000 personas, incluidas las zonas ajardinadas, los arbustos y los árboles. Congregar a un millón de apoyadores devenía físicamente imposible» (Grijelmo, 1997: 156). Ciertamente, El País (de entonces) cumplía en la prensa diaria una función informativa y simbólica crucial.

Ya en democracia, sólo en situaciones muy concretas, el Gobierno (central, autonómico o municipal) toma la iniciativa o se suma rápidamente a la de partidos y movimientos sociales para la masiva movilización de la ciudadanía.

\subsection{Seis ejemplos «del millón»}

En los cuadros 3 y 4 se exponen seis ejemplos de manifestaciones multitudinarias celebradas en la capital, y en las que con un cierto triunfalismo se ha declarado la asistencia de uno o incluso dos millones de ciudadanos. Los ejemplos nos ilustrará sobre la fecha, el lema de la convocatoria, convocantes, pancarta inicial, recorrido, pancartas y gritos, y algunos datos que nos acerquen a los aspectos más cualitativos de la movilización. Vemos a su vez, las unanimidades o discrepancias (guerra de cifras) que se observan en las magnitudes de asistencia ofrecidas por las distintas fuentes. Veremos así los elementos comunes y las diferencias existentes en los casos seleccionados.

Los seis ejemplos (A/F) del cuadro pertenecen al periodo 1981/2004. Tienen en común la defensa de la libertad (A,B,C,D), contra la violencia y el terrorismo

${ }^{22}$ Por falta de rigor o estrategia consciente se observa que con el paso del tiempo, una misma organización o medio, se refiere a una manifestación histórica, combinando cifras de asistentes distintas. Generalmente cifras altas con la movilización «en caliente», y con el tiempo se van rebajando, revaluando así por tanto los eventos presentes (ver Cuadro 4). 


\begin{tabular}{|c|c|c|c|c|c|}
\hline \multirow{7}{*}{ 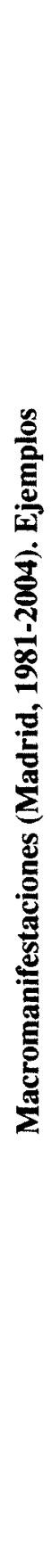 } & $L$ & 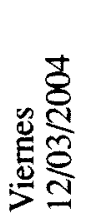 & 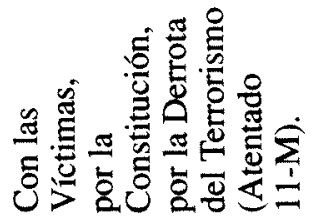 & 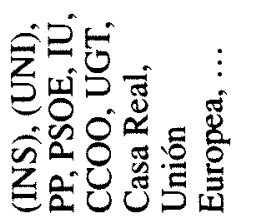 & $\dot{\underline{0}}$ \\
\hline & 101 & 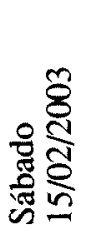 & 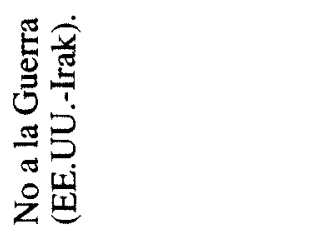 & 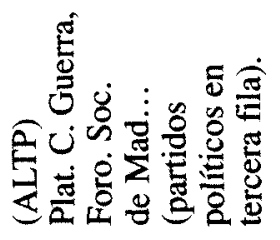 & 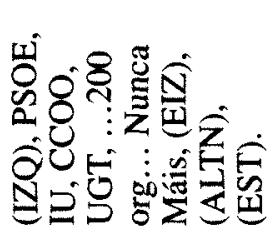 \\
\hline & 0 & 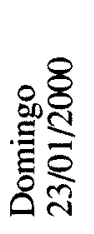 & 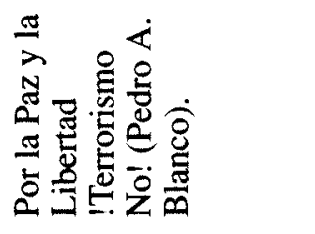 & 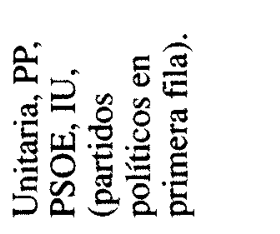 & 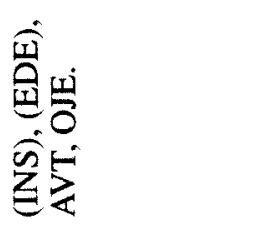 \\
\hline & $u$ & 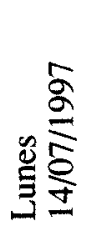 & 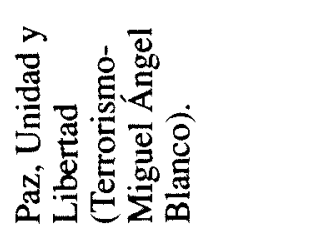 & 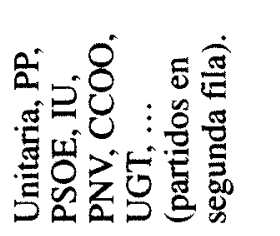 & $\stackrel{\dot{\Omega}}{\underline{Z}}$ \\
\hline & $\infty$ & 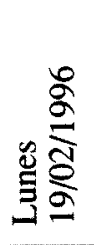 & 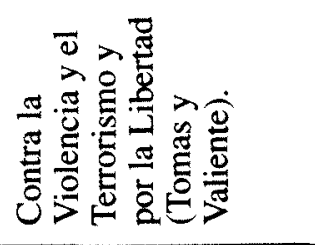 & 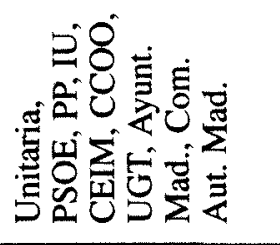 & 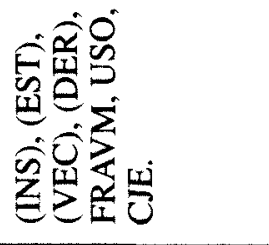 \\
\hline & $\varangle$ & 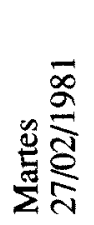 & 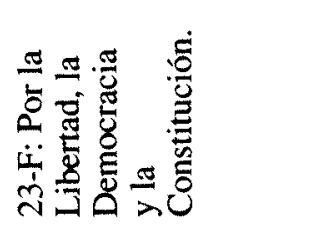 & 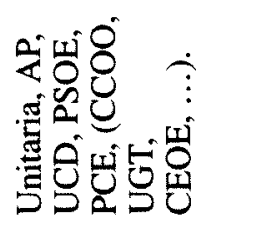 & 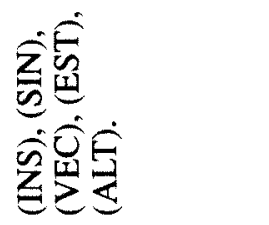 \\
\hline & $\frac{0}{\stackrel{0}{5}}$ & $\begin{array}{l}\text { 胥 } \\
\text { 过 }\end{array}$ & $\stackrel{\mathbb{E}}{\tilde{E}}$ & 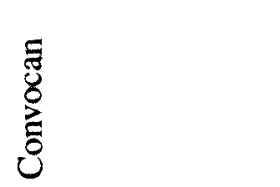 & 䄺 \\
\hline
\end{tabular}




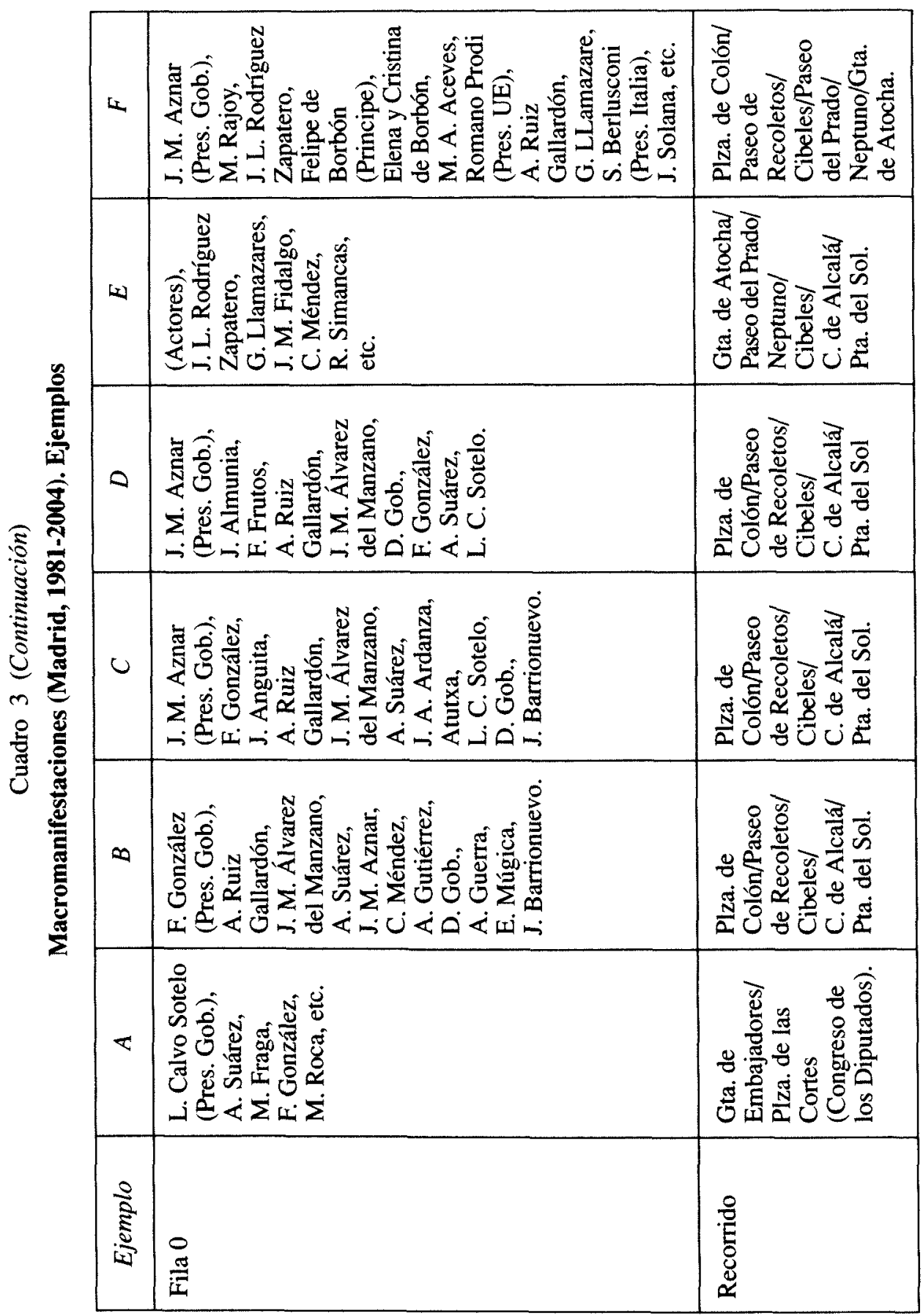

EMPIRIA. Revista de Metodología de Ciencias Sociales. N. ${ }^{\circ}$ 9, enero-junio, 2005, pp. 171-208. 


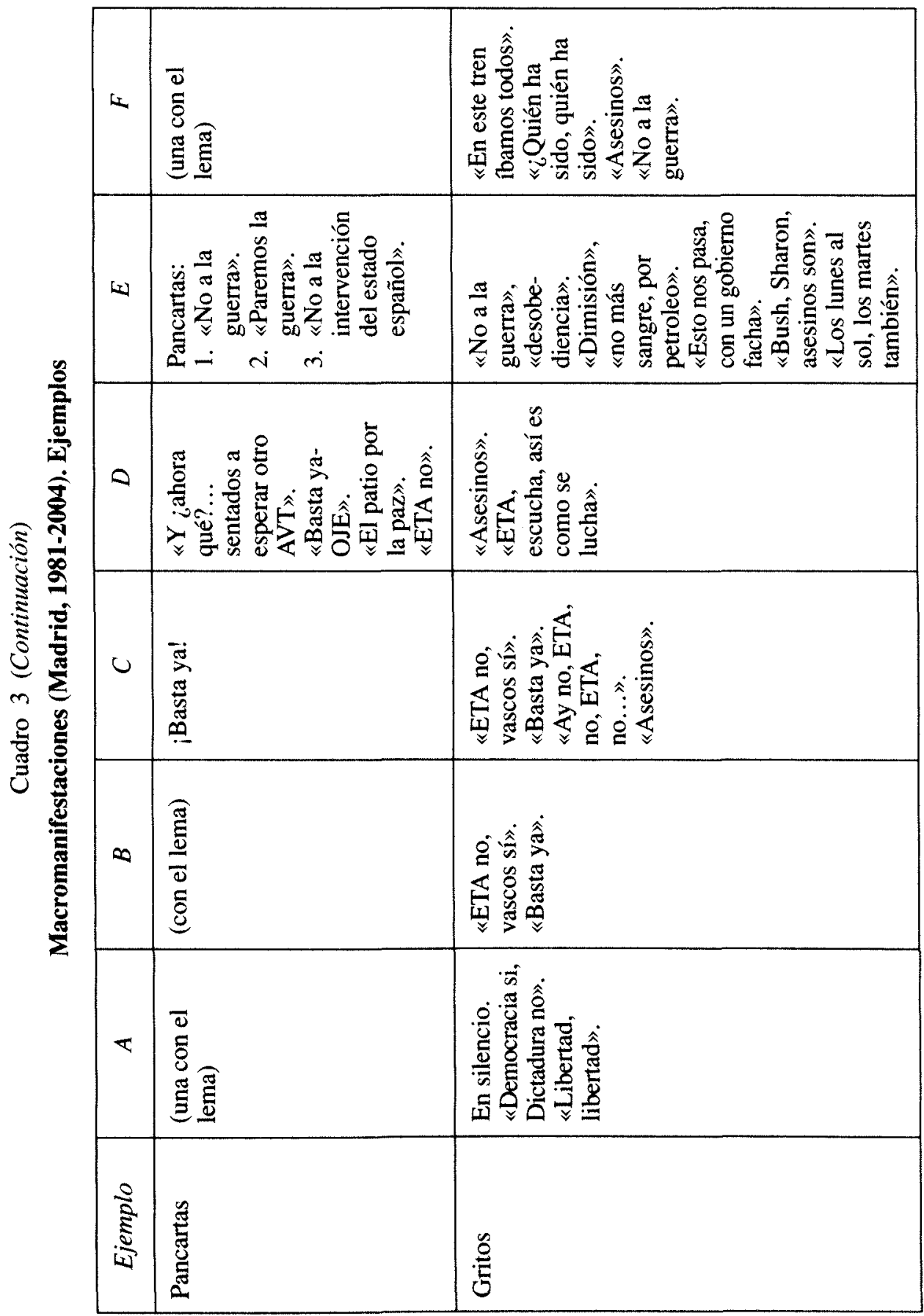




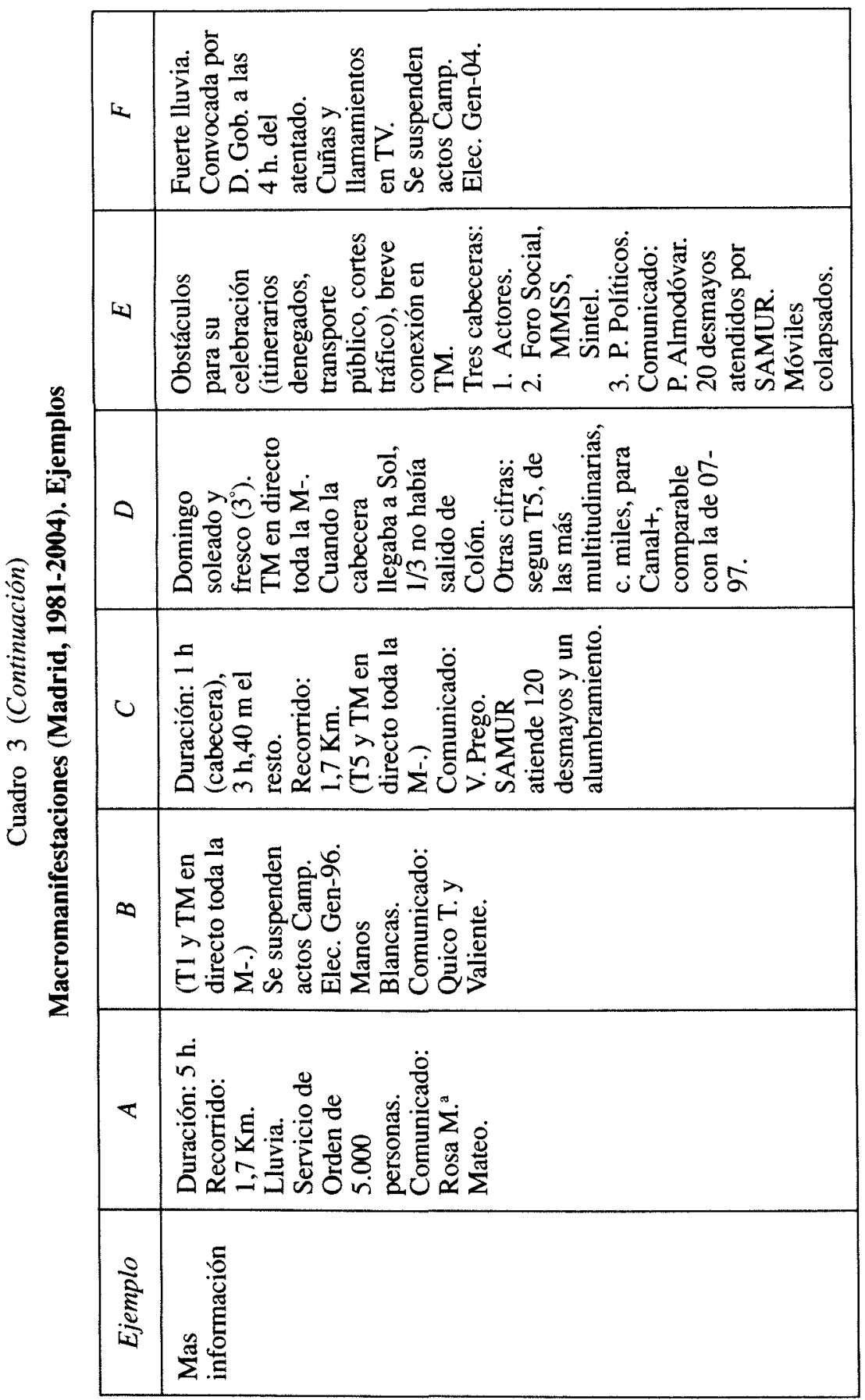


RAMÓN ADELL ARGILÉS MANIFESTÓMETRO: RECUENTO DE MULTITUDES... 201

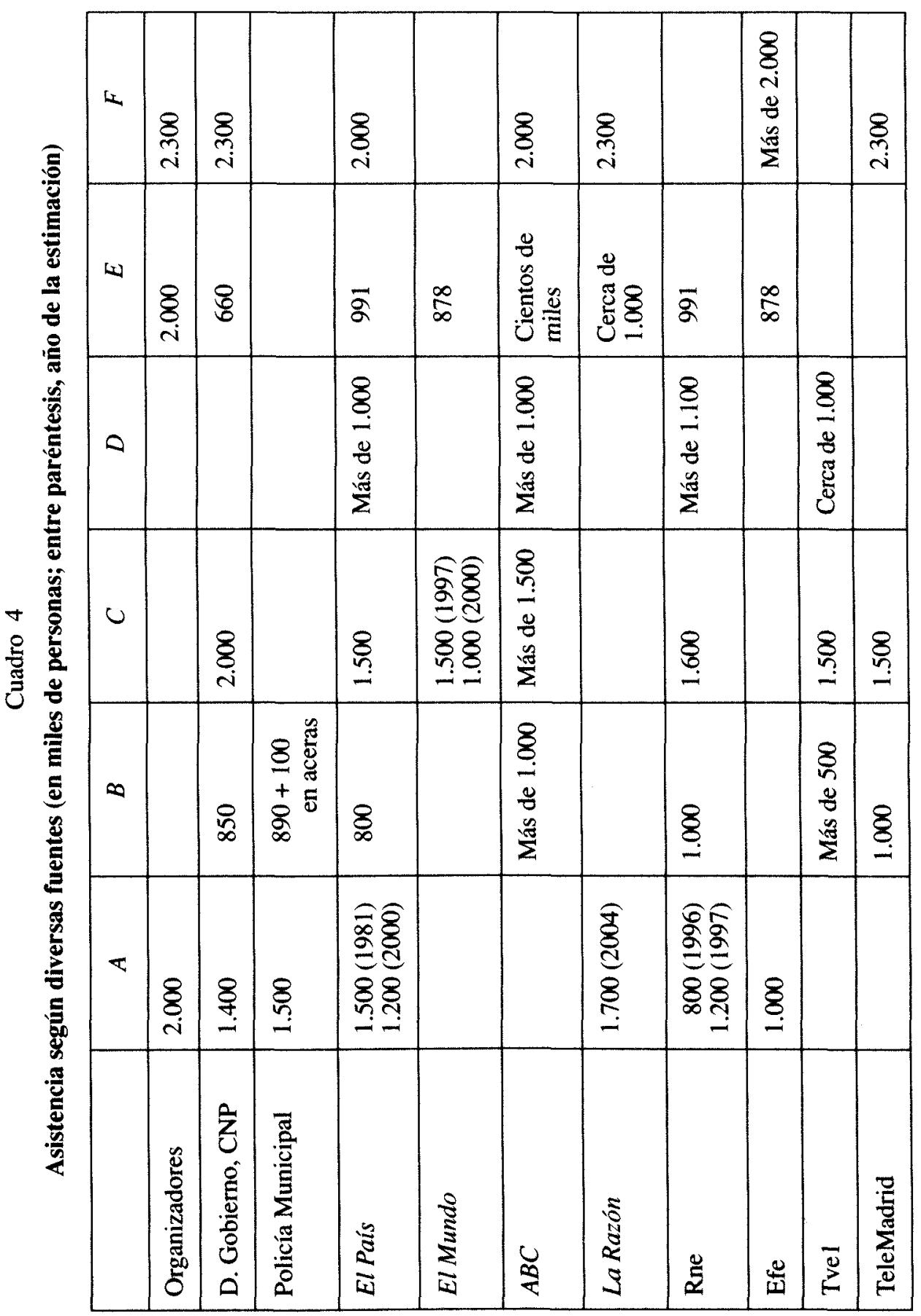

EMPIRIA. Revista de Metodología de Ciencias Sociales. N. ${ }^{\circ}$ 9, enero-junio, 2005, pp. 171-208. ISSN: 1139-5737 
(B,C,D,F), la paz interna (B,C,D,E), o contra la guerra (E), la defensa de la Constitución (A,F), la unidad (C,F), contra el golpismo (A). En todos los casos son reacciones colectivas contra interrupciones de la paz y la democracia. A causa de atentados $(B, C, D, F)$, golpismo (A), o guerra (E). Se generan por la propia necesidad de mostrar la cohesión de la ciudadanía en momentos difíciles. Pero además, toda manifestación tiene destinatarios o una imputación de culpabilidad. Estos son golpistas (A), terroristas de ETA (B,C,D,F?), terroristas de Al Qaeda (F?), los gobiernos de España y Estados Unidos (E,F?). Indirectamente parte de las responsabilidades de los sucesos precipitantes son de los gobiernos a causa de sus políticas (por acción o pasividad), pero en cambio, y generalmente de forma unitaria, los dirigentes se sitúan (al menos brevemente y con cierta polémica) en muchos casos en primera fila. La excepción la tenemos en el caso F, la protesta contra la guerra, en dónde no participa - lógicamente - el Presidente de Gobierno. La protesta careció de apoyo institucional y además se obstaculizó por diversos medios.

Las demás se convierten, de una u otra forma en manifestaciones de adhesión, a la monarquía democrática (A,F), al PP (B,C,D), al PSOE (A,E,F), frente a desestabilizaciones y presagio de cambios de gobierno. En cuanto a mayor asistencia -institucional- de personalidades destaca la más reciente. En el cuadro se describen algunos gritos y pancartas, así como características propias de los actos.

Por tanto, en situaciones de peligro para el sistema político, se recurre a las movilizaciones de adhesión (institucionales, unitarias, o ambas). Riesgos de golpismo o un alto grado de terrorismo pueden llegar a movilizar a sectores de población que tradicionalmente no participan nunca o casi nunca en manifestaciones.

Las convocatorias unitarias reúnen a sectores de la Izquierda y de la Derecha, pero su base sociológica suele ser centrista y moderada, esto es, integrada por una parte de la opinión pública usualmente ajena a las movilizaciones, pero dispuesta a manifestarse, en última instancia, cuando las circunstancias ponen en peligro la continuidad del sistema democrático. Son los «gritos de silencio» de los «vigilantes de la democracia». Se trata de convocatorias reactivas de ira contenida y generalmente en silencio (roto a veces por gritos espontáneos) como muestra de repulsa. Suelen partir de sentimientos de impotencia que, tras la movilización, se convierten en ansiedad contenida e indignación. Los asistentes pertenecen a todos los estratos sociales y a todas las edades, representan asimismo un reflejo de la estructura social y de su abanico ideológico. La diana de las convocatorias es «el pueblo», «la ciudadanía», «los hombres y mujeres de bien», «todos». Son llamamientos a las masas, en el sentido más extenso del concepto.

A diferencia de las manifestaciones de protesta habituales, en estas los resortes estatales y medios de comunicación se vuelcan en «movilizar a todos». Por su necesario efecto propagandístico, gozan del máximo apoyo institucional y máxima cobertura informativa. Las convocatorias institucionalizadas (gubernamentales, institucionales y unitarias) disfrutan de una masiva cobertura infor- 
mativa (antes, durante y después) por parte de los media (oficiales y en democracia, los libres), por lo cual suelen obtener el apoyo masivo de la ciudadanía. Estos ceremoniales colectivos se convierten en hitos y por tanto permanecen largo tiempo en la memoria histórica de una comunidad.

Para el Gobierno, las más movilizaciones más numerosas serían, por orden de mayor a menor: F,C,A,B,E. El resto del cuadro se comenta por sí sólo.

Para finalizar este apartado constatamos también, que cuando «el millón» sale a la calle, se desactivan las micro-protestas (tanto en convocatorias, apoyos y repercusión mediática). Es una auto-paralización generalizada de protestas y reivindicaciones de sectores y movimientos que supeditan sus demandas al interés nacional.

\subsection{Tamaño de las movilizaciones «clásicas»}

Conforme avanza la Transición Política, se producen cada vez más manifestaciones pero en líneas generales con menor asistencia. Lo primero se debe al progresivo aumento de libertades (especialmente la legalidad del derecho de reunión y manifestación) y al aumento de los actores colectivos y temas reivindicativos con la emergencia de los nuevos movimientos sociales (Adell, 1989). Respecto al descenso de la asistencia, salvo las grandes movilizaciones que recordamos todos, se produce una paulatina desmovilización fruto de ciclos de cansancio. En el Gráfico 4 observamos la tendencia explicada.

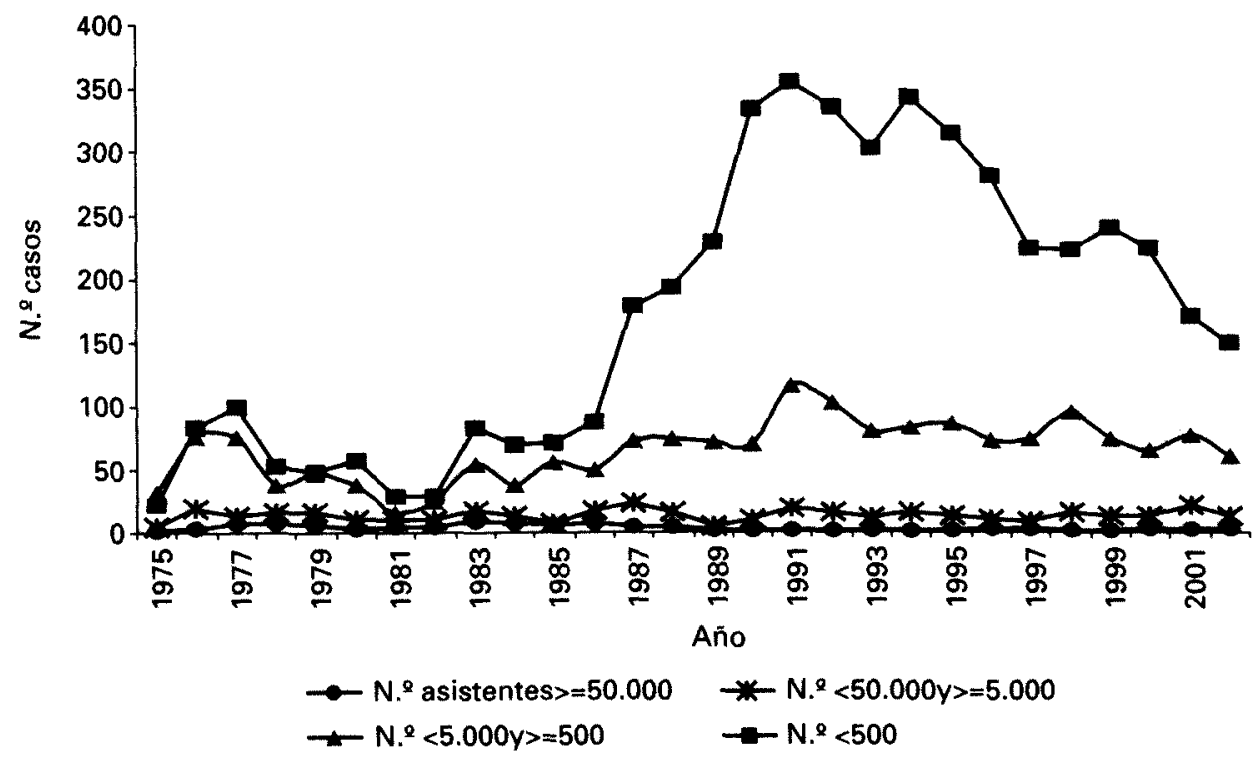

Gráfico 4. Manifestaciones según tamaño. 
De la muestra estudiada, seleccionamos las manifestaciones en función de su tamaño (cálculos propios) y año de celebración. Con ello vemos el peso de la movilización en una serie temporal. Así por ejemplo, los eventos multitudinarios (cohorte $\geq 50.000$ participantes, con una media de 169.000) suponen una parte mínima del total. Se recoge un máximo anual de 9 casos para el año 1983 (Reconversión industrial). Suponen tan sólo un $1,37 \%$ de la muestra total estudiada (7.158 eventos). Además de éstas, existen otras grandes manifestaciones con una asistencia menor de 50.000 personas y mayor de 5.000 (media de 11.600 asistentes a cada una). Se registran entre 4 y 24 (1987) casos anuales y suponen el $5,45 \%$ de la muestra. Más habituales son las protestas menores, pero aún numerosas en cuanto a casos se refiere, con una asistencia de entre más de 500 y menos de 5.000 personas (media de 1.400 asistentes). Salvo el año 1978 (Constitución) y el periodo $1980-1982$ (23-F) tenemos más de 50 casos anuales lo que supone finalmente un $25,57 \%$ de la muestra (una de cada cuatro movilizaciones). Destaca el año 1991 con varios conflictos, entre ellos las protestas vecinales contra la inseguridad ciudadana.

Finalmente, la manifestación más habitual (el 67,62\%), no consigue reunir más de medio millar de personas (media de 140 personas). Se refleja aquí una extensa pluralidad de microconflictos (actores y temas). Su uso se dispara en la etapa de Gobierno PSOE, desde la aprobación de la Ley de Reunión de 1985 más facilitadora, hasta la Ley de Seguridad Ciudadana (Ley Corcuera-1992), más restrictiva. La cúspide se sitúa en 1991, con 356 casos. Descienden progresivamente desde 1996. Estas manifestaciones «clásicas», van dejando paso a nuevas formas de protesta virtual gracias a las nuevas tecnologías.

\section{Y LAS HUELGAS OTRO TANTO...}

Tampoco existe un «huelgómetro» creíble cuando nos referimos a las repercusiones reales de una huelga. Se trata pues de otro ejemplo clásico de manipulación numérica de las dimensiones del conflicto y, por tanto, de desinformación de la ciudadanía. Las organizaciones convocantes (sindicatos, Comités de Empresa, etc.) de los paros o huelgas maximizan su impacto mientras que patronales (Estatales, privadas, etc.) minimizan su apoyo al máximo. Todo ello, en caso de que finalmente den algún porcentaje de su seguimiento. No hay que olvidar, aun siendo obvio, que desde siempre el reconocimiento de un mayor o menor seguimiento de una huelga se asocia con la justeza y oportunidad de las reivindicaciones y ello puede determinar un giro en las negociaciones y el resultado final de la demanda. Por su parte los medios de comunicación, recogen los datos de una parte u otra - y en el mejor de los casos ambas- sin aportar datos propios (más que «historias de vida» de trabajadores o ciudadanos que se posicionan a favor o en contra del conflicto). Estamos otra vez ante el creer o no creer. En casos de huelgas generales, existen algunos otros indicadores que ayudan a medir el impacto de los paros (afluencia a centros comer- 
ciales, estadísticas anuales de horas perdidas/huelgas/año, consumo eléctrico de $\mathrm{Kw} / \mathrm{h}$, velocidad del tráfico).

Para ver los «márgenes» que tiene la dimensión del conflicto hemos recogido una serie de casos en donde con independencia del tamaño de la empresa, sector o ciudadanía convocada al paro, tenemos porcentajes de seguimiento de ambas partes. No entraremos aquí en los éxitos o fracasos de los resultados del conflicto, para una parte u otra, ni del coste real que sobre la ciudadanía han tenido estos largos y periódicos conflictos en donde servicios esenciales públicos y privados se han visto afectados. Todo ello merecería un estudio concreto caso por caso. Igualmente la existencia de servicios mínimos, en ocasiones del $100 \%$, confunden aún más las cifras que unos u otros aportan. Hemos recogido 56 casos de huelgas concretas, sectoriales o generales del periodo 1976-2003 (ámbito Estatal o de Madrid, según los casos).

Se observan amplias diferencias que separan ambas fuentes. En muchos casos los porcentajes ofrecidos por unos y otros suman entorno a cien. Los extremos de polarización entre fuentes lo tenemos en la reciente huelga del 20-J2000 y el paro del 10-A-2003.

Es fácil e «independiente» e incluso lógico (por convención a veces entre actores) pensar que el porcentaje de huelguistas es la media sistemática entre patronal o gobierno y sindicatos. En nuestra opinión, resulta simplista esta deducción pues el margen de manipulación interesada de los actores en conflicto es muy amplio, y las lógicas de dominación (política, económica) activa sobre los medios hacen imposible el conocimiento real del conflicto.

Respecto a las diferencias de cuantificación entre patronal y gobierno tenemos algún ejemplo. Así en la Huelga del 27-E-1994 mientras desde la administración se afírma que fue secundada por el $32,3 \%$ de los trabajadores, la CEOE rebaja la cifra al $26 \%$. Por tanto, las patronales minimizan más el conflicto que los poderes políticos. También hemos observado casos curiosos o novedosos, como por ejemplo una huelga de telefónica (23-6-1995) en donde el paro es secundado por el $65 \%$ de los trabajadores según fuentes sindicales mientras que para la empresa, su impacto es nulo, alegando la automatización del servicio.

Dada la tendencia del poder a minimizar el conflicto y la contraria por parte de los sindicatos podemos pensar que la cifra real de huelguistas oscilaría entre un mínimo patronal y un máximo sindical. Si hacemos la simple media de una fuente y otra, de los casos estudiados, obtendríamos la siguiente constatación: las huelgas han sido secundadas por un $52,45 \%$ de los trabajadores ( $77 \%$ según convocantes, y el $27,9 \%$ según la patronal). Obviamente este dato, tan sólo nos refleja «estilos comunicativos» para exagerar o minimizar el conflicto, ya que el $49,1 \%$ de orquilla entre unos y otros nos muestra una alta polarización de las partes y nos recuerda que, lejos aún de la huelga «tipo», cada caso es una situación particular. 


\section{BIBLIOGRAFÍA}

ADELL, R. (1989): La transición politica en la calle- Manifestaciones de grupos y masas en Madrid (1975-1987). Colección Tesis Doctorales Universidad Complutense n. ${ }^{\circ}$ 283, Madrid.

- (1996): «Referéndum OTAN, in memoriam», Viento Sur, n. ${ }^{\circ}$ 25, Madrid, pp. 114121.

- (2002): «Nacionalismo y polarización social: análisis y reflexiones sobre la movilización contra el terrorismo», en Robles Morales, J. M. (Comp.) (2002): El reto de la participación. Movimientos sociales y organizaciones: una panorámica comparativa. Ed. Antonio Machado, Col. Mínimo Tránsito-Visor, Madrid, pp. 65-110.

Almirall, Miquel y ConCA, Vicent (2000): «Las manis segons la Guardia Urbana: Els pans i els peixos» (13-10-2000) y «Calcular per no desinformar» (26-12-2000) en Contrastant.net..y..llibertat.com.

ATAN (2004): http://www.atan.org/urbanismo/pg/manipulacion.htm .

CANETt, Elías (1960): Masa y poder. Alianza, Muchnik, Madrid, ed. 1997.

CASAsús, Josep Maria (2001): «Contemos bien los manifestantes», La Vanguardia, Barcelona, $8 / 7 / 2001$.

Cicourel, Aaron V. (1982): El método y la medida en Sociología. Madrid, E. Nacional, (e.o. 1964).

Delgado, Manuel; Horta, Gerard y MonNET, Nadja (2003): «Els usos simbòlics de la trama urbana: Deambulacions rituals d' indole civil a Barcelona (1977-2003)», Ponencia IV Congrès ACS, Reus.

DuPUY, Jean-Pierre (1999): El pánico. Gedisa, Barcelona.

EsPaDA, Arcadi (2003): Diarios. Espasa Calpe, Pozuelo.

ESPINA, Wilfredo (2001): «Cartas al Director», La Vanguardia. Barcelona 14/6/2001.

FAVRE, Pierre (dir.) (1990): La manifestation. Presses de Sciences Po, París.

Fillieule, Olivier (1996): Contestation sociale el ordre public à Paris (1-7-68/31-1-96) Manuel de Codage «Parismanifs», París.

García FerRando, M.; IbÁÑez, J. y Alvira, F. (comps.) (1986): El análisis de la realidad social. Métodos y técnicas de investigación social. Alianza, Madrid.

GrANOVETTER, Mark (1990): «Modelos de umbral de conducta colectiva», Zona Abierta, n. ${ }^{\circ}$ 54-55, Madrid, pp. 137-166.

GriJelmo, Álex (1997): El estilo del periodista. Taurus, Madrid.

Helbing, Dirk; KelTSCH, J. y MOLNÁR, P. (1997): «Modelling the evolution of human trail systems», Nature, 388, pp. 47-50.

IBÁÑEZ, J (1985): «La medida de la sociedad». En REIS, n. ${ }^{\circ} 29$, enero-marzo, pp. 85-128.

- (1997): A contracorriente. Ed. Fundamentos, Madrid.

LECHNER, Norbert (1986): «La conflictiva y nunca acabada construcción del orden deseado». CIS Monografías, n. ${ }^{\circ}$ 91, Madrid.

LIZCANO, Emmánuel (2002): «Las matemáticas de la tribu europea: un estudio de caso». Texto de II International Congress on Ethnomathematics, Ouro Preto, Brasil, 5-8 de agosto.

MC ADAM, Doug; TARrow, S.; Tilly, Ch. (2005): Dinámica de la contienda política. Hacer Editorial. Barcelona.

MoRIN, Edgar (2004): La violencia del mundo. Paidós, Asterisco9, Barcelona.

Moscovici, Serge (1981): L'Age des foules. Ed. Complexe, France, 2. ${ }^{\mathrm{a}}$ ed., 1985. 
Noelle-Newman, E. (1985): La espiral del silencio. Opinión pública: nuestra piel social. Paidós, Barcelona.

RudÉ, George (1994): La Europa revolucionaria: 1783-1815. Siglo XXI, Madrid.

TILLY, Charles (1998): «Conflicto político y cambio social», en Ibarra, P. y Tejerina, B. (eds.): Los movimientos sociales. Transformaciones políticas y cambio cultural. Trotta, Madrid, pp. 25-41.

Vázquez, Jesús M. ${ }^{a}$ y PlazA, Lia-Ana (1985): La opinión en la calle (Asistencia a las manifestaciones en Madrid). Instituto de Sociología Aplicada de Madrid, Salamanca. 


\section{RESUMEN}

Los indicadores clásicos de democracia-formal (voto, afiliación partidista, cultura política, etc.) han ignorado tradicionalmente la emergencia de otros fenómenos participativos - menos decisivos y «convencionales»- de la práctica democrática cotidiana, como es el llamado «poder de la calle». En este artículo se intenta profundizar en la interpretación del indicador «movilización ciudadana» y sus dinámicas expresivas y simbólicas. La «guerra de cifras» que se produce tras cada acto multitudinario o la mítica «cifra del millón» en actos de masiva movilización ciudadana nos muestran la manipulación y desinformación existente entorno a las dimensiones reales del conflicto o su posible representatividad y las profundas divergencias entre cifras oficiales, las de los organizadores y las de las agencias de información. La falta de observadores independientes (y por tanto de recuentos objetivos de grupos, masas o multitudes) nos indica la necesidad de establecer parámetros objetivos para analizar los fenómenos de acción colectiva y movilización.

Pero sería ingenuo creer que las masas son sólo una suma de individuos más o menos cuantificables, o que responden por igual y mecánicamente en cada convocatoria. No sólo importa el número, sino el «ambiente». Existen importantes elementos cualitativos que no podemos dejar de analizar, ya que inciden también en el resultado de la demanda.

\section{ABSTRACT}

Classical indicators of formal democracy (vote, party affiliation, political culture, etc.) have traditionally ignored the emergence of other paticipative phenomena in the everyday democratic practice, like the so-called «street power». This paper tries to study in depth the indicator of «civic mobilization» and its expressive and symbolic dynamics. The manipulation and disinformation around the real dimensions of conflicts and its representativeness is shown by the «war of numbers» given after demonstrations and the mythical «figure of one million». So, we look at the deep divergences between sources (official, organizers and news agencies). The lack of independent observers (and so the lack of objective counts of people) points out the need of create the parameters to analyze these phenomena of collective action.

But it would be ingenious to think that masses are only a sum of people who react in the same mechanical way in each call. Not only is the number important but also the «environment». There are important qualitative factors that we should analyze, given their impact in the outcome of the demand. 